\title{
Temporal control and response strength in a free -operant psychophysical procedure
}

Lori M. Lieving

West Virginia University

Follow this and additional works at: https://researchrepository.wvu.edu/etd

\section{Recommended Citation}

Lieving, Lori M., "Temporal control and response strength in a free -operant psychophysical procedure" (2003). Graduate Theses, Dissertations, and Problem Reports. 1926.

https://researchrepository.wvu.edu/etd/1926

This Dissertation is protected by copyright and/or related rights. It has been brought to you by the The Research Repository @ WVU with permission from the rights-holder(s). You are free to use this Dissertation in any way that is permitted by the copyright and related rights legislation that applies to your use. For other uses you must obtain permission from the rights-holder(s) directly, unless additional rights are indicated by a Creative Commons license in the record and/ or on the work itself. This Dissertation has been accepted for inclusion in WVU Graduate Theses, Dissertations, and Problem Reports collection by an authorized administrator of The Research Repository @ WVU.

For more information, please contact researchrepository@mail.wvu.edu. 
Temporal Control and Response Strength in a Free-Operant Psychophysical Procedure

\author{
Lori M. Lieving
}

\author{
Dissertation Submitted to the \\ Eberly College of Arts and Sciences \\ at West Virginia University \\ in partial fulfillment of the requirements \\ for the degree of \\ Doctor of Philosophy \\ in \\ Psychology
}

Kennon A. Lattal, Ph.D., Chair

Todd Knealing, Ph.D.

Kevin Larkin, Ph.D.

B. Kent Parker, Ph.D.

Michael Perone, Ph. D.

Department of Psychology

Morgantown, West Virginia

2003

Keywords: temporal control, response strength, resistance to change, pigeons, key peck 


\section{Abstract \\ Temporal Control and Response Strength in a Free-Operant Psychophysical Procedure}

\section{Lori M. Lieving}

The purpose of the present experiments was to examine the relation between timing and response strength. Pigeons responded on a two-component multiple schedule consisting of the freeoperant psychophysical procedure, in which trials lasted $50 \mathrm{~s}$. During the first $25 \mathrm{~s}$ of each trial, responding on the left key was reinforced according to a variable interval (VI) schedule of reinforcement. During the second $25 \mathrm{~s}$ of each trial, responding on the right key was reinforced according to a VI schedule of reinforcement. In Experiment 1, responding in one component was maintained by a VI 30-s schedule (rich component) and responding in the other component was maintained by a VI 120-s schedule (lean component). In Experiment 2, responding in both components was maintained by a VI 60 -s schedule, but reinforcement consisted of 6.5 -s access to grain (rich component) in one component and 1-s access to grain in the other (lean component). Responding then was disrupted by adding response-independent food delivery during the intertrial interval and by prefeeding. In general, the results of both Experiments 1 and 2 are consistent with the existing literature: response rates and ET50s (the index of timing) were more disrupted during the lean components than during the rich components. The effects of the disruptors provided partial support for the Behavior Theory of Timing (BeT). In addition, during the rich components, time was overestimated relative to estimations of time during the lean components. It is suggested that temporal control and response strength are related in the sense that both measures tend to vary in a manner consistent with predictions based on the BeT and the response strength literature. 


\section{Acknowledgements}

I would like to begin my thanking the members of my committee. First, I would like to thank Andy for graciously welcoming me to his lab and providing the patience and support necessary for the completion of this dissertation. We were able to easily hit the ground running and make a smooth transition when we began working together. I thank him for that because I never could have completed this dissertation in a timely manner without him. I thank Todd Knealing, Kevin Larkin, Kent Parker, and Mike Perone for their cooperation in scheduling and completing meetings and for their useful feedback on this document. The experiments contained in this dissertation are better because of them. I also would like to thank Todd Knealing for making the trek from Baltimore to Morgantown so that I could defend this dissertation.

I thank David Schaal for his contributions to this dissertation. Although he was not directly involved with this project, he will always indirectly contribute to all the work that I do. He spent years assisting me in my development as a researcher, a writer, a teacher, and a friend. Although he is no longer present at WVU, he is often the voice of reason that I hear when I need to make a decision. I would also like to thank my fellow graduate students, both past and present, as well as the rest of faculty in the Behavior Analysis program. In particular, I would like to thank Carolina Aguilera, Stephanie da Silva, Adam Doughty, Chad Galuska, Todd Knealing, Gregory Lieving, Amy Odum, Timothy Shahan, and Tammy Wade. These students have served as my colleagues, my classmates, my mentors, and my friends throughout the duration of my graduate career. In many ways, I have learned more from them than anyone else. I thank them all because through discussions in class, in the hallways, at lab meetings, and over beers, they have made me a better behavior analyst. 
Thanks are also due to my family, specifically my mother, Alana, and my brothers Brian and Stephen. Throughout my entire life, they have been an amazing support group. They have wept with me when times were bad and have celebrated with me when times were good. The most important thing, however, is that they have always been there for me, despite the occasional jokes about my choice to be a life-long student. This dissertation, nor any other accomplishment of mine, would have been possible without that support.

Finally, I would like to thank my husband, Greg, for understanding the importance of this dissertation and all of my other commitments related to graduate school. He has never complained about the necessity for me to remain in Morgantown on weekends or to be absent on visits because of my running schedule. He has simply said he would wait for me until I was finished. He has listened to rants, long discussions about data, and my frantic ravings the night before my defense and has supported me through all of it. Greg, thank you for loving me, no matter what. 
Table of Contents

$\begin{array}{lll}20 & \text { Page }\end{array}$

Acknowledgements.....................................................ii

List of Figures.........................................................

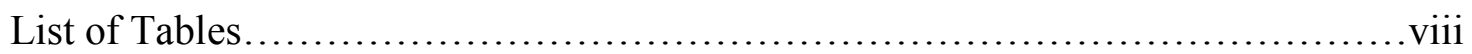

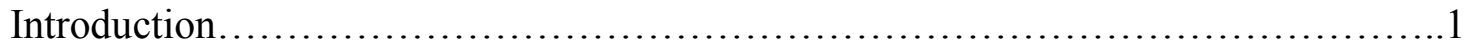

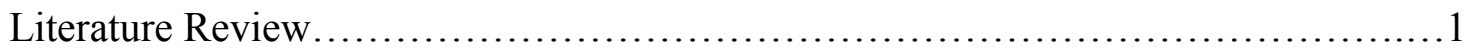

Timing and Timing Theories.........................................

Support for the Behavioral Theory of Timing...........................6

Reinforcement Parameters and Response Strength.......................10

Timing and Response Strength.........................................13

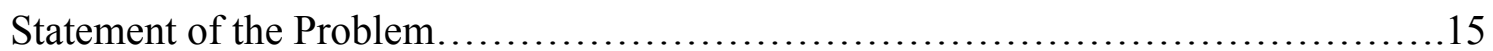

General Method.......................................................... 18

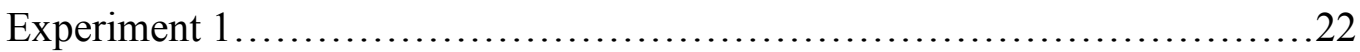

Procedure..................................................22

Results.....................................................22

Discussion................................................. 37

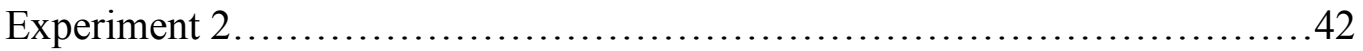

Procedure....................................................42

Results...................................................44

Discussion...................................................56

General Discussion........................................................

Conclusions....................................................66 
Effects of Disruptors........................................66

Baseline Differences in Performance................................67

Temporal Control and Response Strength........................69

Summary...................................................... 70

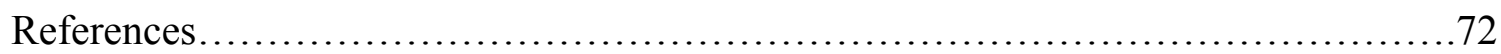




\section{List of Figures}

Figure $\quad$ Page

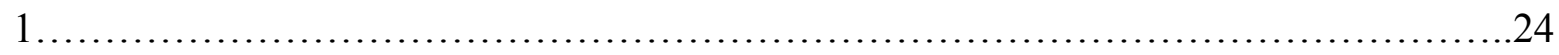

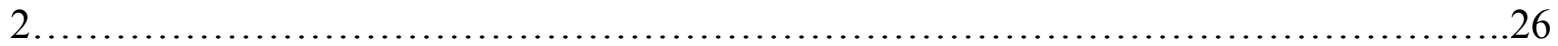

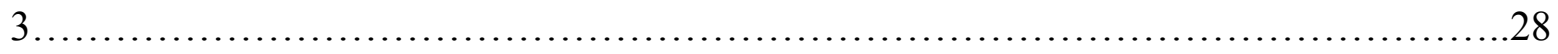

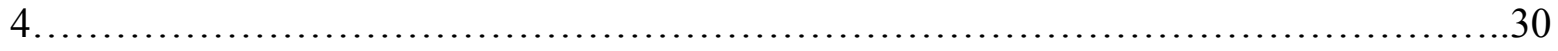

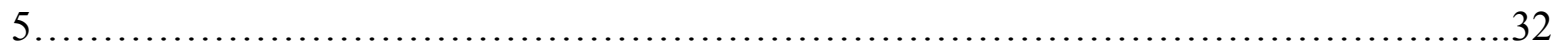

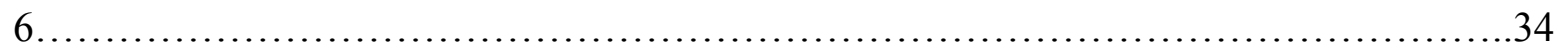

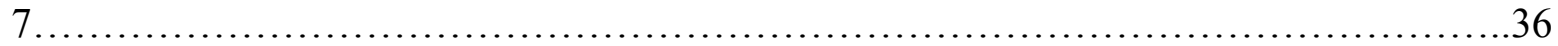

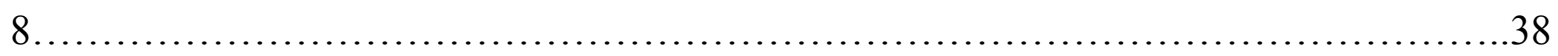

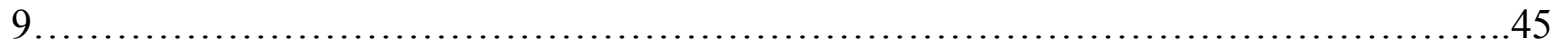

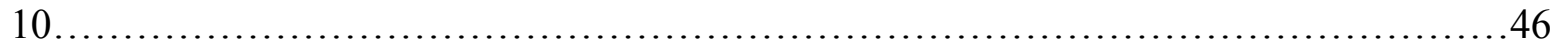

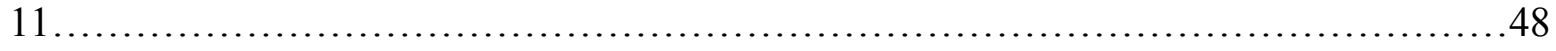

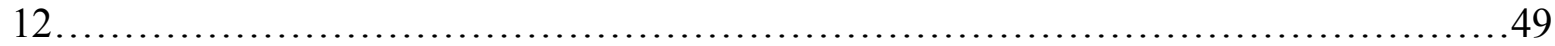

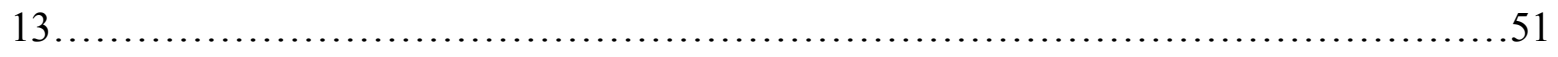

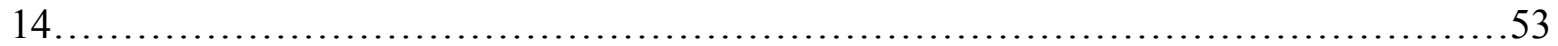

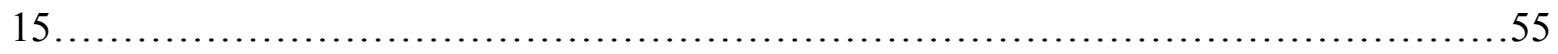

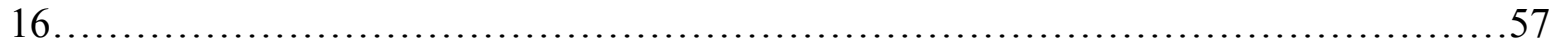




\section{List of Tables}

Table

Page

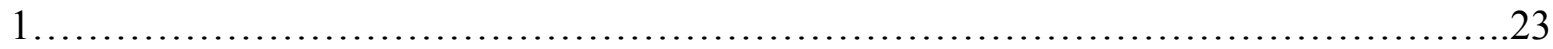

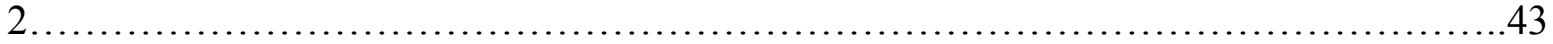




\section{TEMPORAL CONTROL AND RESPONSE STRENGTH IN A FREE-OPERANT}

\section{PSYCHOPHYSICAL PROCEDURE}

Temporal discrimination has been explained in several ways. In the behavioral theory of timing (BeT), Killeen and Fetterman $(1988,1993)$ proposed that a hypothetical pacemaker emits pulses that are correlated with the passage of time. One unique characteristic of the BeT is that it asserts that variables such as reinforcement rate, magnitude, and probability will alter temporal discrimination. When reinforcement conditions are improved, the pacemaker will emit pulses at a faster rate, and the organism responds as though more time has passed than actually has. Placing emphasis on the effects of reinforcement variables allows the findings in timing research to be integrated with other areas of research. Research on response strength may be related to timing because the variables that alter timing, such as reinforcement rate, duration, and probability, are the same variables that determine response strength. The purpose of the present paper, therefore, was to examine the relation between timing and response strength. Two variables that affect timing and response strength were examined. In Experiment 1, responding on a temporal discrimination task was maintained by rich and lean rates of reinforcement in a multiple schedule. In Experiment 2, responding was maintained by long or short reinforcer durations. Responding then was disrupted by food delivery in between components of the multiple schedule and by providing food prior to experimental sessions. To the extent that timing and response strength are related, timing should be more resistant to disruption when the temporal discrimination is maintained by a rich rate of reinforcement or by long reinforcer durations relative to lean reinforcement or by short reinforcer durations. 
This review provides a description of timing and several methods that have been used to assess it. A review of the behavioral theory of timing then will be provided. The behavioral theory of timing asserts that reinforcement parameters such as rate or magnitude are important determinants of timing. Reinforcement variables such as rate and magnitude also have been shown to determine response strength. Thus, the notion of response strength and how it may be related to timing then will be discussed.

\section{Timing and Timing Theories}

The duration of a stimulus, like other stimulus properties such as wavelength, intensity, or position, is a discriminable property of a stimulus (Skinner, 1938; Stubbs, 1968). Time has three properties that differentiate it from other stimulus properties (Catania, 1970). First, time is irreversible. The five seconds that just passed cannot be repeated or removed. Second, time cannot vary discontinuously. The rate at which time passes cannot be increased, decreased or stopped. Finally, a specific receptor for the duration of a stimulus has not yet been identified, unlike other properties of a stimulus that can be sensed (i.e., brightness, color). Despite the differences between time and other properties of a stimulus, organisms can be trained to attend to, respond in relation to, and discriminate the passage of time. Such a discrimination can be inferred from differential responding as time elapses, such as in a fixed-interval (FI) schedule of reinforcement, or differential responding after stimuli of different durations have been terminated, such as the interval bisection task (Church \& Deluty, 1977). For purposes of the present paper, only the peak procedure and the free-operant psychophysical procedure will be described.

The peak procedure (Catania, 1970; Roberts, 1981) consists of two different types of trials: reinforced trials and nonreinforced peak trials. On reinforced trials, the first response after 
a fixed time elapses produces reinforcement (i.e., an FI schedule). On peak trials, the stimulus associated with reinforced trials remains on for a duration that is often two to three times that of the reinforced trials. Trials end when the trial duration elapses and no reinforcement is presented. After training, responding on the peak trials occurs at low rates early in the interval, reaches a maximum or peak rate near the time reinforcement delivery would occur on reinforced trials, and declines afterward. The time at which the peak rate occurs, the "peak time," is the index of timing in this procedure.

The free-operant psychophysical procedure (FOPP; Bizo \& White, 1994a, 1994b; Stubbs, 1968, 1979, 1980) involves pigeons responding on two different keys. During, for example, 50-s trials, left-key responding is reinforced at variable intervals during the first $25 \mathrm{~s}$ and is not reinforced during the second $25 \mathrm{~s}$ of the trial. Left-key responding typically occurs at high rates during the first half of the trial and falls to lower rates during the second half of the trial. Rightkey responding is not reinforced during the first $25 \mathrm{~s}$ of the trial and is reinforced at variable intervals during the second $25 \mathrm{~s}$. Right-key responding typically occurs at lower rates during the first $25 \mathrm{~s}$ and then increases to higher rates during the second $25 \mathrm{~s}$. The 50 -s trials are divided into intervals, or bins, of several seconds and left- and right-key responses occurring during different bins are accumulated. Proportions of right-key responses are calculated by dividing right-response totals in successive bins by total left and right responses in each bin and then are plotted as a function of time in the 50-s trial. Proportions of right responses are typically low during the first half of the trial and increase as the time in the trial increases. The point at which left and right key responding are equal (i.e., the estimated time where $50 \%$ of responding occurs on the right key or ET50) is typically at the midpoint of the trial (i.e., $25 \mathrm{~s}$ ) and often serves as the index of timing. 
The peak procedure and the FOPP measure timing in somewhat different ways, but both tasks require responding during the temporal stimulus as opposed to responding after the temporal stimulus has elapsed. It is assumed, therefore, that each procedure measures the same timing process. This finding has been supported by research examining the effects of the same variables on performance maintained by the two tasks either within or across experiments. Thus, the effects of reinforcement variables (e.g., Bizo \& White, 1994a, 1994b; Grace \& Nevin, 2000), drugs from several pharmacological classes (e.g., Knealing \& Schaal, 2002; Kraemer, Randall, Dose, \& Brown, 1997; Maricq, Roberts, \& Church, 1981), and physiological manipulations, such as the effects of central 5-hydroxytryptamine (5-HT) depletion (Chiang, Al-Ruwaitea, Ho, Bradshaw, \& Szabadi, 1999; Morrisey, Ho, Wogar, Bradshaw, \& Szabadi, 1994; Morrisey, Wogar, Bradshaw, \& Szabadi, 1993) have had comparable effects on timing, regardless of the specific task that was used.

Performance on the FOPP and other temporal discrimination procedures has been explained in several different ways. Theories of time perception usually involve a pacemakercounter model where a pacemaker is posited to emit pulses, which are accumulated by some type of counter (Gibbon, 1977; Gibbon \& Church, 1981; Gibbon, Church, \& Meck, 1984). The scalar expectancy theory (SET), for example, proposes a hypothetical pacemaker, a switch that connects the pacemaker to an accumulator, and the involvement of both short- and long-term memory. The number of pulses accumulates while an animal is "timing" a stimulus. Pacemaker pulses are accumulated and compared to the number of pulses associated with the expected time of reinforcement. Temporal judgments are based on the output of a comparator that matches the number of accumulated pulses in short-term memory to those in long-term memory. Choices, 
therefore, are made based on the similarity between remembered and recently presented durations.

Killeen and Fetterman $(1988,1993)$ proposed an alternative account of timing by suggesting that timing is behaviorally mediated. The BeT holds that pulses from the hypothetical pacemaker move the organism through sequential behavioral states. Adjunctive behaviors correlated with different states may precede reinforcement of the response controlled by the temporal stimulus. The adjunctive behaviors then provide the basis for the organism's conditional discrimination as to its position in time. For example, adjunctive responses may take the form of crouching in the corner of the chamber, pacing, extending the neck, or pecking various locations in the chamber. The BeT suggests that these adjunctive behaviors occur in an orderly fashion throughout an interval. Therefore, if an organism is in a behavioral state correlated with a long duration and then is required to discriminate the passage of time, it would be more likely to respond long if it is engaged in a behavior previously correlated with the long state than if it is engaged in behavior that is not well correlated with being in the long state (Laties, Weiss, Clark, \& Reynolds, 1965; Laties, Weiss, \& Weiss, 1969).

Another important feature of the $\mathrm{BeT}$ is that the rate at which the pacemaker pulses is determined by reinforcement variables. The rate of the pacemaker increases when variables such as the rate of reinforcement are increased, and the rate of the pacemaker decreases when the rate of reinforcement is decreased. Changing the rate of the pacemaker then alters temporal discrimination. According to the BeT, when the rate of the pacemaker is increased, the organism will be moved through behavioral states faster, thus reaching the final state sooner and will then respond as though more time has passed than actually has (i.e., the organism will "overestimate" 
time). Conversely, when the rate of the pacemaker is decreased, the organism will move through the behavioral states more slowly and will underestimate the passage of time.

Support for the Behavioral Theory of Timing

A major assumption of the $\mathrm{BeT}$ is that the pacemaker rate is determined by reinforcement parameters associated with the temporal stimulus. Pacemaker rate varies as a function of reinforcer rate (Bizo \& White, 1994a; Fetterman \& Killeen, 1991; MacEwen \& Killeen, 1991; Morgan, Killeen, \& Fetterman, 1993), duration (Bizo \& White, 1994b; Fetterman \& Killeen, 1991; Grace \& Nevin, 2000; MacEwen \& Killeen, 1991), and probability (Grace \& Nevin, 2000; Killeen, 1991). Providing a review of several of these studies will be the focus of this section. Morgan, Killeen, and Fetterman (1993) examined the effect of reinforcement rate associated with a temporal stimulus on the timing of that stimulus. Trials consisted of presenting a red keylight for 10 or $20 \mathrm{~s}$ followed by the illumination of the side keys. Responses on the left key were reinforced if the 10-s (short) stimulus was presented and responses on the right key were reinforced if the 20-s (long) stimulus was presented. Once responding was accurate (i.e., most response occurred on the left key when the short stimulus was presented and on the right key when the long stimulus was presented), reinforcement probability was reduced to 0.25 and, on $25 \%$ of the trials, a 14-s stimulus was presented. Responding after the 14 -s stimulus was not reinforced (i.e., it was a probe test) and was used as a measure of temporal discrimination. Because $14 \mathrm{~s}$ was the temporal midpoint of the two trained stimuli (i.e., the geometric mean of 10 and $20 \mathrm{~s}$ ), it was expected that responding after both stimulus durations would be distributed evenly during the 14 -s stimulus presentation. Therefore, any deviations from $50 \%$ would indicate changes in temporal discrimination. Following this training, the temporal discrimination trials were discontinued and half of the subjects were exposed to a low rate of response-independent 
food presentations in the presence of the red keylight while the other half of the subjects were exposed to a high rate of response-independent food presentations. Subjects then responded on a modification of the baseline task, in which half of the trials consisted of the 14-s stimulus while the other half consisted of either the 10- or 20-s stimulus, but reinforcement was not delivered (i.e., testing was conducted in extinction). The probability of responding "long" after the 14-s stimulus was compared between the groups. With a history of a higher rate of responseindependent food presentations, there was an increased tendency to respond on the long key after the 14-s stimulus. Conversely, with a history of a lower rate response-independent food presentations, there was a decreased tendency to respond on the long key.

After testing was complete, responding again produced reinforcement. One session was conducted immediately after the test phase in which all correct responses to the 10- or 20-s stimulus were reinforced. This procedure increased the rate of reinforcement from zero (extinction during testing) to approximately 3 reinforcers per minute and provided another assessment of the effects of changes in reinforcer rate, but one in which the change occurred within the testing context. When the reinforcer rate was increased, responding on the long key increased after the 14-s stimulus, replicating the findings of reinforcer manipulations made before testing occurred. Thus, when a higher rate of response-independent or response-dependent food presentations was associated with the temporal stimulus, either before or during testing, subjects overestimated the passage of time. The effect of the reinforcement rate associated with a temporal stimulus has been replicated using the FOPP (e.g., Bizo \& White, 1994a) and similar temporal discrimination procedures (e.g., Fetterman \& Killeen, 1991) while reinforcement rate was manipulated both between experimental conditions (e.g., Fetterman \& Killeen, 1991) and within individual sessions (e.g., MacEwen \& Killeen, 1991). 
Reinforcement probability also alters timing. Killeen (1991) described an unpublished study examining the effects of different probabilities of reinforcement on timing. Pigeons were trained to peck the left key at $8 \mathrm{~s}$ after the beginning of trial, the center key at $16 \mathrm{~s}$ and the right key at $32 \mathrm{~s}$. Response rates on the left key were highest during the early portion of the trial, highest on the center key during the middle portion of trial, and highest on the right key during the later portions of the trial. The probability of reinforcement was then changed from 1.0 to 0.75. Reducing reinforcement probability produced shifts in performance consistent with the BeT: switching from the left to the center key and from the center to the right key occurred at a later point in the interval relative to when the reinforcement probability was 1.0. Thus, BeT predicts that when reinforcement probability is decreased, the pacemaker rate will decrease and an underestimation of time will occur. Grace \& Nevin (2000) examined the effects of different reinforcement probabilities on behavior maintained by the peak procedure within a multiple schedule. On half of the reinforced trials, responding was reinforced with a probability of 1.0 while responding on the other half was reinforced with a probability of 0.33 . When the reinforcement probability was higher, responding began earlier in the interval and response rates peaked earlier relative to when the reinforcement probability was low.

Another reinforcement parameter that alters the temporal control of behavior is reinforcer duration. For example, Bizo and White (1994b) examined performance maintained by the FOPP. At the beginning of a 50-s trial, the left and right keys were lit red and green respectively. Initially, responding was reinforced on a variable-interval (VI) schedule of reinforcement with 4$\mathrm{s}$ access to food as the reinforcer. After approximately 30 sessions, the reinforcer duration was reduced to $1.5 \mathrm{~s}$. Next, the reinforcer duration was increased to $4 \mathrm{~s}$. Increasing the reinforcer duration decreased the ET50, which is consistent with an overestimation of time. Grace \& Nevin 
(2000) also examined the effects of different reinforcer durations on behavior maintained by the peak procedure within a multiple schedule. On half of the reinforced trials, responding was reinforced with 4.5-s access to grain while responding on the other half of reinforced trials was reinforced was 1.5 -s access to grain. When the reinforcer duration was longer, responding began earlier in the interval and response rates peaked earlier relative to when the reinforcer duration was short.

In the BeT, Killeen and Fetterman $(1988,1993)$ assumed that the speed of the pacemaker was determined by reinforcement parameters such as reinforcement rate, probability and duration. There is evidence that reinforcement parameters influence temporal discrimination. When variables such as reinforcement rate, duration, and probability are increased, an overestimation of time is produced. The BeT suggests that this overestimation of time is due to an increase in the rate of the pacemaker. Hence, a faster pacemaker should result in a bias to respond as though more time has passed than actually has, and a slower pacemaker should result in a bias to respond as though less time has passed than actually has. Examining timing performance in this manner allows comparisons to be made between timing and other phenomena such as contrast effects and foraging strategies (Killeen, 1991). One area of research that may be interesting to examine in the context of timing is response strength. As suggested above, an important determinant of a temporal discrimination is the rate, duration, or probability of reinforcement. These variables also are important determinants of response strength. How reinforcement variables are related to response strength therefore will be discussed in the next section of this review. 


\section{Reinforcement parameters and response strength}

It is often suggested that reinforcement strengthens behavior and increases the rate of responding (Skinner, 1938). Nevin (1974) proposed resistance to change as a method for measuring response strength. One way to assess the relative strength of behavior is to attempt to disrupt performance and determine for how long behavior will persist when the contingencies have been changed. Measuring resistance to change often involves maintaining behavior on a multiple schedule with different reinforcement schedules in each component. Responding will stabilize according to the conditions in each component. If some variable that reduces the rates of responding is introduced, such as extinction, systematic satiation, or response-independent food presentations between components, the behavior that undergoes the smallest reduction, relative to baseline performance, is considered stronger. Similar to research on timing, variables such as reinforcement rate, duration, and immediacy determine response strength. Behavior maintained by a higher rate of reinforcement (Nevin, 1974; Nevin, 1984; Nevin, Mandell, \& Atak, 1983), larger reinforcer magnitude or longer reinforcer duration (Harper, 1996; Nevin, 1974; Rau, Pickering, \& McLean, 1996), or immediate reinforcement (Bell, 1999; Grace, Schwendiman, \& Nevin, 1998; Nevin, 1974) persists longer in the face of disruption relative to conditions when behavior is maintained by a low rate of reinforcement, small magnitude reinforcer, short reinforcer, or delayed reinforcement.

Nevin (1974) provided a comprehensive analysis of the variables that determine the strength of behavior maintained during multiple schedules. The general procedure involved arranging a multiple schedule in which responding was maintained by different reinforcer rates, durations, or delays. Responding then was disrupted by presenting response-independent food during the blackouts between components. Relative response rates were calculated by expressing 
the rate of responding in the different components maintained during the first hour after the introduction of response-independent food as a proportion of baseline response rates. Responseindependent food during blackouts generally decreased responding. When responding was maintained by VI 1-min and 3-min schedules of reinforcement, higher rates of responding were maintained by the VI 1-min schedule. In addition, relative response rates maintained by the VI 1min schedule were higher than relative response rates maintained by the VI 3-min schedule when response-independent food was introduced.

Nevin (1974) also examined responding that was maintained by a multiple VI 1-min VI 1-min schedule of reinforcement. In one component, reinforcement was 7.5 -s access to grain while reinforcement in the other component was 2.5 -s access to grain. When responseindependent food was introduced, relative response rates were higher in the component associated with the longer reinforcer duration. Finally, the effects of delayed reinforcement on response strength were examined. Responding was maintained on a multiple VI 1-min VI 1-min schedule of reinforcement. Across conditions, delays to reinforcement were manipulated such that the total delay between the two components was always $10 \mathrm{~s}$. For example, one condition examined the effects of delays of 2.5 and $7.5 \mathrm{~s}$. When response-independent reinforcement was added, response rates decreased in both components, but higher relative response rates were maintained when responding was maintained by more immediate reinforcement.

Nevin's (1974) original findings have been replicated and extended. For example, Nevin, Mandell, and Atak (1983) maintained responding on a two-component multiple schedule in which green and red key lights signaled different VI schedules (which arranged 129, 42, or 10 reinforcers per hour). Two VI schedules were compared in each condition (i.e., 129 and 42 reinforcers per hour, 42 and 10 reinforcers per hour, 129 and 10 reinforcers per hour) and the red 
key was always correlated with the higher rate of reinforcement. The multiple schedule alternated with periods in which the keys were dark and food was delivered independently of a response (i.e., arranged 60,120, 180, or 300 reinforcers per hour). As the number of reinforcers delivered during dark-key periods increased, response rates in the presence of both green and red keys decreased. Responding in the presence of the red key, the key that was correlated with a higher rate of reinforcement, was more resistant to the effects of the response-independent food deliveries than responding maintained during the green key. Therefore, responding maintained in the presence of the red key could be said to have higher response strength relative to responding in the presence of the green key.

Grace, Schwendiman, and Nevin (1998) examined the effects of delays of reinforcement on response strength and replicated the findings of Nevin (1974). A two-component multiple schedule consisting of separate VI 40-s schedules was arranged. After responding was stable, the schedule in one component was changed to a VI $37 \mathrm{~s}$ with a 3-s nonresetting, unsignaled delay to reinforcement. Responding then was disrupted by providing food $30 \mathrm{~min}$ prior to the experimental session (i.e., systematic satiation or prefeeding) and by conducting sessions in which no reinforcers were delivered in either component. In general, delayed reinforcement maintained lower response rates compared to immediate reinforcement. When prefeeding or extinction disrupted responding, higher relative response rates were maintained in the component with immediate reinforcement.

Reinforcer duration also affects response strength. Harper (1996) examined responding that was maintained by a multiple VI 120-s VI 120-s schedule of reinforcement. Reinforcement in Component 1 consisted of 2-s access to grain and reinforcement in Component 2 consisted of 6-s access to grain. Once responding was stable, response-independent food was delivered during 
the blackouts between components. The addition of response-independent food delivery decreased response rates, but higher relative response rates were maintained when reinforcer duration was longer.

\section{Timing and response strength}

The variables that are important in determining how a stimulus is timed are also important in determining response strength. When the reinforcement rate correlated with a stimulus is increased, organisms will overestimate the duration of a temporal stimulus and the strength of responding occurring in the presence of that stimulus will increase. Increasing the reinforcer duration will also produce overestimations of time and will produce responding that is more resistant to change relative to responding that is maintained by shorter reinforcer durations. Only one study, however, has explicitly examined the relation between timing and response strength. Grace and Nevin (2000) examined the effect of various reinforcement variables on performance maintained by the peak procedure and subsequently assessed the response strength of the performance. All of the experiments involved a multiple schedule that exposed the subjects to two FI schedules that differed in terms of reinforcement duration, rate or probability. In one experiment, the first response after $20 \mathrm{~s}$ produced 4.5 -s access to grain in one component and 1.5-s access to grain in the other component. Typical performance was generated on peak trials that lasted $60 \mathrm{~s}$ : response rates were low during the early portions of the trial, then reached a maximum or peak rate at approximately the same time as when reinforcers were delivered during the FI schedules, and then decreased for the remainder of the trial. The BeT would predict that the longer reinforcer duration would produce an overestimation of time, which would be indicated by a decrease in the time at which the peak response rate occurred. In addition, responding maintained by a longer reinforcer duration should also be more resistant to change 
relative to responding maintained by the shorter reinforcer duration. The findings of Grace and Nevin (2000) are consistent with these predictions: increasing the reinforcer duration decreased the peak time and also produced behavior that was more resistant to change. In another experiment, the effects of reinforcement rate on timing and response strength were examined. In one component, the first response after 10 s produced reinforcement. Occasionally, the trial was extended to last $30 \mathrm{~s}$ (i.e., peak trials). In the other component, the first response after $30 \mathrm{~s}$ produced reinforcement and on occasional peak trials, the duration of the trial was $90 \mathrm{~s}$. Increasing the overall reinforcement rate (by decreasing the FI value), decreased the peak time and produced behavior that was more resistant to change. Finally, they examined the effects of different reinforcement probabilities and found comparable results: higher reinforcement probability produced an overestimation of time and produced behavior that was more resistant to disruption.

One potential problem with the findings of Grace and Nevin (2000) on the effects of reinforcement rate on timing and response strength is that the interval to be timed is confounded with reinforcement rate. One important aspect of animal timing is that the mean and standard deviations of temporal estimates are proportional to the duration to be timed. This property is based on Weber's law and has been called the scalar property of timing (e.g., Gibbon, 1977). Therefore, when using two different intervals to assess timing, the relative variability in responding will be similar across the intervals while the absolute variability of responding will be greater for responding in relation to a longer interval. Weber's law, therefore, predicts that the temporal discrimination of a longer duration will necessarily be more variable because of the scalar property of timing, which may suggest that longer durations do not produce stimulus control at the same level as shorter durations (Bizo \& White, 1994a; Gibbon, 1977). This effect 
is evident in the data of Grace and Nevin (2000) because the peak functions based on the longer duration (30 s) are wider then those for the short duration (10 s). Therefore, the temporal discrimination of the long duration may have been less resistant to change because of a lower level of stimulus control, due to the scalar property of timing, rather than the lower rate of reinforcement. In addition, some of the differences Grace and Nevin (2000) reported are relatively small, though statistically significant and only data averaged across all subjects were shown. Perhaps the parameters and procedure used were not sufficient enough to produce robust differences in behavior.

\section{Statement of the Problem}

The BeT attempts to account for timing by positing that a hypothetical pacemaker emits pulses that are correlated with the passage of time. These pulses are also correlated with adjunctive behaviors that occur in an orderly fashion as an interval elapses. One distinguishing characteristic of the $\mathrm{BeT}$ is that it suggests that the rate at which the pacemaker emits pulses is determined by reinforcement variables such as rate, duration, and probability. Increasing reinforcement rate, duration, or probability will produce an overestimation of the duration of a temporal stimulus. In addition, increasing reinforcement rate, duration, or probability correlated with a response will increase the strength of that response. The question remains, however, as to the extent to which timing and response strength are related. When the reinforcement conditions associated with a temporal discrimination are improved, is that temporal discrimination strengthened?

Grace and Nevin (2000) provided the only examination of the relation between timing and response strength and it is was flawed for the reasons outlined above. The purpose of the present set of experiments, therefore, was to further examine the relation between timing and 
response strength. Responding was maintained on a multiple-schedule version of the FOPP described by Bizo and White (1994a, 1994b) using different reinforcement rates and durations. The FOPP was chosen because both the reinforcement rate and duration can be altered without changing the temporal structure of the procedure. Either different VI schedules or different reinforcer durations maintained responding, but the duration of the trial remained the same across conditions. Using the FOPP, therefore, avoided the confound between the interval to be timed and reinforcement rate. Reinforcement rate and duration were examined because of the specific predictions made about these variables based on the BeT and the general findings concerning response strength. Based on the $\mathrm{BeT}$, a higher rate of reinforcement or longer reinforcer duration should lead to an overestimation in time. In addition, a higher rate of reinforcement or longer reinforcer duration should produce behavior that is more resistant to change relative to behavior maintained by a lower reinforcement rate or shorter reinforcer duration when disrupted by response-independent food during intertrial intervals (ITI's) or prefeeding.

A secondary goal of the present experiments was to assess whether the effects of the disruptors would be consistent with the BeT. The BeT assumes that the speed of the pacemaker is proportional to reinforcer rate, duration, or probability. Because the disruptors may be construed as changes in overall reinforcement rate, or at least changes in overall access to food, BeT makes several predictions for responding in the present experiments. Addition of responseindependent food increases the total number of reinforcer deliveries during the session and, therefore, should increase the speed of the pacemaker, which should decrease the ET50. On the other hand, prefeeding does not change the overall rate of reinforcement during the session, but does increase the overall access of food for the pigeon. It may be reasonable to expect that 
prefeeding will be similar to response-independent food in that the speed of the pacemaker will be increased, and the ET50 will be decreased.

Finally, theories of timing predict no differences in timing between responding in the rich and lean components during baseline. Even though initially the pacemaker speed should be faster in the richer component, as indicated by a lower ET50 relative to responding in the leaner component, performances should recalibrate so that there is no difference between the measures of timing in the components (Bizo \& White, 1994a; Fetterman \& Killeen, 1991; MacEwen \& Killeen, 1991; Morgan, Killeen, \& Fetterman, 1993). The pigeons will learn different numbers of behavioral states for each component resulting in no differences in timing across components. Although there is evidence to support the lack of baseline differences in timing when different reinforcement variables are changed (Bizo \& White, 1994a; Fetterman \& Killeen, 1991; MacEwen \& Killeen, 1991; Morgan, Killeen, \& Fetterman, 1993), Grace and Nevin (2000) found differences in timing consistent with BeT across all of the reinforcer manipulations: the peak rate occurred at an earlier time in the interval during the richer components relative to the leaner components. Grace and Nevin (2000) suggested that this might have occurred because the experiments were conducted using multiple schedules, which may have prevented recalibration from occurring whereas in those studies reporting no differences in baseline performance, reinforcement conditions were changed across conditions. Although the present experiments were not specifically designed to test this suggestion, the experiments were conducted using multiple schedules, so it is worth noting whether baseline differences were produced.

Thus, three questions were posed in each experiment: first, whether there were systematic differences in temporal control or the rate of responding when performance was disrupted; second, if the effects of the disruptors on temporal control were consistent with BeT; and third, 
whether there were baseline differences in temporal control between the rich and lean components.

\section{General Method}

\section{Subjects}

The subjects were eight experimentally naïve White Carneau pigeons (four in each experiment). Upon arrival at the animal colony, pigeons were allowed free access to food for two weeks. Once daily weights were stable, access to food was restricted so that weights were reduced to $80 \%$ of free-feeding weight over a 2 -week period. Pigeons were maintained at either 70 or $80 \%$ free-feeding weight through post-session feedings as necessary. Because response rates for several pigeons were relatively low, weights were reduced to $70 \%$ of free-feeding weights. In Experiment 1, Pigeons 545, 510, and 573 were maintained at $80 \%$ free-feeding weight and Pigeon 738 was maintained at 70\% free-feeding weight. In Experiment 2, Pigeons 858 and 553 were maintained at $80 \%$ free-feeding weight while Pigeons 778 and 562 were maintained at $70 \%$ free-feeding weight. When not in experimental sessions, pigeons were individually housed in a temperature-controlled colony under a 12:12 hr light:dark cycle with free access to water and health grit.

\section{Apparatus}

Four custom-made experimental chambers constructed of wood with aluminum front panels were used. Each chamber was $33 \mathrm{~cm}$ wide, $31 \mathrm{~cm}$ from front to back, and $37.5 \mathrm{~cm}$ high. Three response keys were mounted $26 \mathrm{~cm}$ from the floor on the front panels. Colored lights served as discriminative stimuli and were behind each key. The keys were $2.85 \mathrm{~cm}$ in diameter and required a force of approximately $0.19 \mathrm{~N}$ to record a response. A 28-V 1.1-W lamp $7 \mathrm{~cm}$ above the center key served as the houselight. A rectangular aperture $(5 \mathrm{~cm} \mathrm{x} 7 \mathrm{~cm}) 16 \mathrm{~cm}$ below 
the center key provided access to a solenoid-operated food hopper. Photocells located on each side of the hopper aperture detected hopper entry. Hopper durations began timing when photocell beams were broken by hopper entry. During hopper presentations, the houselight and keylights were extinguished and the hopper was lit white. Extraneous sounds were masked by white noise and chamber ventilation fans. Contingencies were programmed and data collected by microcomputers located in an adjacent room.

\section{Procedure}

\section{Pretraining.}

Pigeons were acclimated to the chambers and then trained to eat from the food hopper. Based on pigeons' latency to place their head in the hopper (i.e., break the photocell beam inside the hopper aperture), a computer program gradually decreased the hopper duration and increased the time between hopper presentations as the pigeons placed their heads in the hopper more rapidly. Sessions were terminated following 40 hopper presentations. When pigeons reliably placed their heads in the hopper with short latencies after the hopper was raised, key pecks were autoshaped. During autoshaping, after a varying amount of time averaging $60 \mathrm{~s}$, a key was lit green or red for $6 \mathrm{~s}$ followed by presentation of the hopper for $4 \mathrm{~s}$. Pecks to a lit key resulted in immediate hopper presentation. The key colors were presented in random order 18 times for a total of 36 hopper presentations. Autoshaping continued until pigeons reliably and with short latencies pecked all key color and position combinations necessary for the experiment.

\section{FOPP Training.}

A multiple schedule of different FOPP trials was used. Trials lasted $50 \mathrm{~s}$ and began when both side keys were lit either green or red. The green key signaled the lean component (low reinforcement rate or short reinforcer duration) and the red key signaled the rich component 
(high reinforcement rate or long reinforcer duration). Initially, on all trials, responses to left key during the first $25 \mathrm{~s}$ of the trial were reinforced according to a VI 15-s schedule of reinforcement (Fleshler \& Hoffman, 1962) and responses to the right key were not reinforced. Responses to the right key during the second $25 \mathrm{~s}$ of the trial were reinforced according to a VI 15-s schedule and responses to the left key were not reinforced. The schedule associated with the left key timed only during the first half of the trial and the schedule associated with the right key timed only during the second half of the trial. Reinforcers that were scheduled but not delivered during a trial were held over until the next trial. There were 15 trials of each type (lean and rich) and trials were separated by a 15-s ITI. During the ITI, all keylights and the houselight were extinguished. A 3-s changeover delay (COD) was used so that a reinforcer was not delivered before at least $3 \mathrm{~s}$ has elapsed since a switch from responding on one key to another had occurred. The VI schedule was increased by 15 -s increments every 3 to 4 sessions until the terminal value was reached (see below for terminal VI values). Sessions were conducted six to seven days per week and sessions lasted 32.5 minutes.

\section{Disruptors.}

The effects of two disruptors were studied once responding was stabilized. Stability was defined as the absence of a trend in response rates and ET50s (see below) for at least 5 consecutive sessions in both components. Disruptor test sessions occurred only if the pigeon's weight was within $15 \mathrm{~g}$ of its established target weight ( $70 \mathrm{or} 80 \%$ free-feeding weight). If the pigeon's weight was outside this range, a session was not conducted. This event occurred only after the largest amounts of prefeeding. Response-independent food deliveries were arranged to approximate VT schedules of 5, 15, and 30 s. During the VT 5-s test condition, responseindependent food was delivered 3 times in each 15-s ITI. During the VT 15-s test condition, 
response-independent food was delivered once during each 15-s ITI and during the VT 30-s test condition, response-independent was delivered at some point during one of two 15-s ITI's. Each 15-s ITI was divided into 151 -s intervals. At the beginning of each ITI, numbers were then chosen from a list representing the 1-s intervals of the ITI, indicating the interval of the ITI in which response-independent food would be delivered. During the VT 5-s test condition, three numbers were chosen from a list of 15 intervals and put in order from smallest to largest. During the VT 15-s test condition, one number was chosen from a list of 15 intervals. During the VT 30$\mathrm{s}$ test condition, one number was chosen from a list of 30 intervals (two ITI's). If the number was between one and 15, the response-independent food would be delivered during the current ITI and if the number was greater than 15 , the response-independent food would be delivered during the next ITI. Response-independent food delivery was arranged this way to ensure that food deliveries occurred at varying times throughout the ITI's, but were evenly distributed across a session, avoiding potential long intervals (or several ITI's) without response-independent food delivery. Five sessions at each of these schedule values occurred, and at least 15 sessions of the FOPP baseline procedure separated each test. Conditions were changed when performance on the FOPP did not change systematically for at least five consecutive sessions. The second disruptor was prefeeding (i.e., satiation). Each pigeon was fed increasing amounts of grain 30 min prior to each session. Testing continued until the first session in which responding did not occur for 10 minutes. The amounts of grain given prior to experimental sessions occurred in the following order: $5,7.5,12.5$, and $22.5 \mathrm{~g}$ for three sessions each. Larger amounts of grain (i.e., 42.5 or $82.5 \mathrm{~g}$ ) were given for three sessions each when $22.5 \mathrm{~g}$ of grain failed to eliminate responding. Immediately prior to beginning the experimental session, any uneaten grain was weighed, and the weight recorded. 


\section{Experiment 1: Effects of Reinforcement Rate}

\section{Procedure}

\section{FOPP Training.}

The VI schedule was increased by 15 -s increments every 3 to 4 sessions, as noted. During lean trials, the VI scheduled was increased until reaching the terminal value of a VI 120-s schedule. During rich trials, the terminal schedule was a VI 30-s schedule. Reinforcement consisted of 3-s access to grain.

\section{Disruptors.}

Table 1 shows the order of conditions and the number of sessions in each condition. For two pigeons (545 and 738), the first disruptor was the delivery of response-independent food during the 15-s ITI. For the other two pigeons (510 and 573), the order of disruptor test sessions was reversed so that the first disruptor test was prefeeding and the second was VT food delivery. For two pigeons (545 and 510), the VT tests were conducted in ascending order (VT 30, 15, and $5 \mathrm{~s}$ ) while VT tests were conducted in descending order (VT 5, 15, and $30 \mathrm{~s}$ ) for the other two pigeons (738 and 573).

Results

Figure 1 shows mean response rates (pecks/min) on left (open circles) and right keys (filled squares) during the VI 120-s component (left column) and the VI 30-s component (right column) across twenty 2.5-s bins of each trial for each pigeon. Each graph represents the mean of the last six sessions of the first baseline condition. In general, response rates tended to be higher during the VI 30-s component than during the VI 120-s component across all pigeons. For all conditions and pigeons, response rates on the left key were highest during the early portions of the 50-s interval and decreased later in the interval to zero or near-zero rates. Response rates on 
Table 1.

Order of conditions, number of sessions for baseline and test conditions, and the largest amount of food given during prefeeding (PF; and consumed during prefeeding $(\mathrm{g})$ ), for each pigeon in Experiment 1.

\begin{tabular}{|c|c|c|c|c|c|c|c|c|c|c|c|c|}
\hline \multirow{3}{*}{$\begin{array}{l}\text { Condition } \\
\text { Baseline }\end{array}$} & \multicolumn{3}{|c|}{ Pigeon 545} & \multicolumn{3}{|c|}{ Pigeon 738} & \multicolumn{3}{|c|}{ Pigeon 510} & \multicolumn{3}{|c|}{ Pigeon 573} \\
\hline & Order & Sessions & s PF amt. & Order & Session & is PF amt. & Order & Session & Is PF amt. & Order & Sessions & s PF amt. \\
\hline & & 63 & & & 17 & & & 46 & & & 15 & \\
\hline VT $30 \mathrm{~s}$ & 1 & 5 & & 3 & 5 & & 2 & 5 & & 4 & 5 & \\
\hline Baseline & & 45 & & & 22 & & & 36 & & & 25 & \\
\hline VT $15 \mathrm{~s}$ & 2 & 5 & & 2 & 5 & & 3 & 5 & & 3 & 5 & \\
\hline Baseline & & 26 & & & 72 & & & 20 & & & 37 & \\
\hline VT $5 \mathrm{~s}$ & 3 & 5 & & 1 & 5 & & 4 & 5 & & 2 & 5 & \\
\hline Baseline & & 17 & & & 18 & & & 75 & & & 68 & \\
\hline Prefeeding & 4 & 13 & $42.5(39.8)$ & 4 & 13 & $42.5(40.2)$ & 1 & 15 & $42.5(42)$ & 1 & 16 & $82.5(36.2)$ \\
\hline
\end{tabular}


VI $120 \mathrm{~s}$
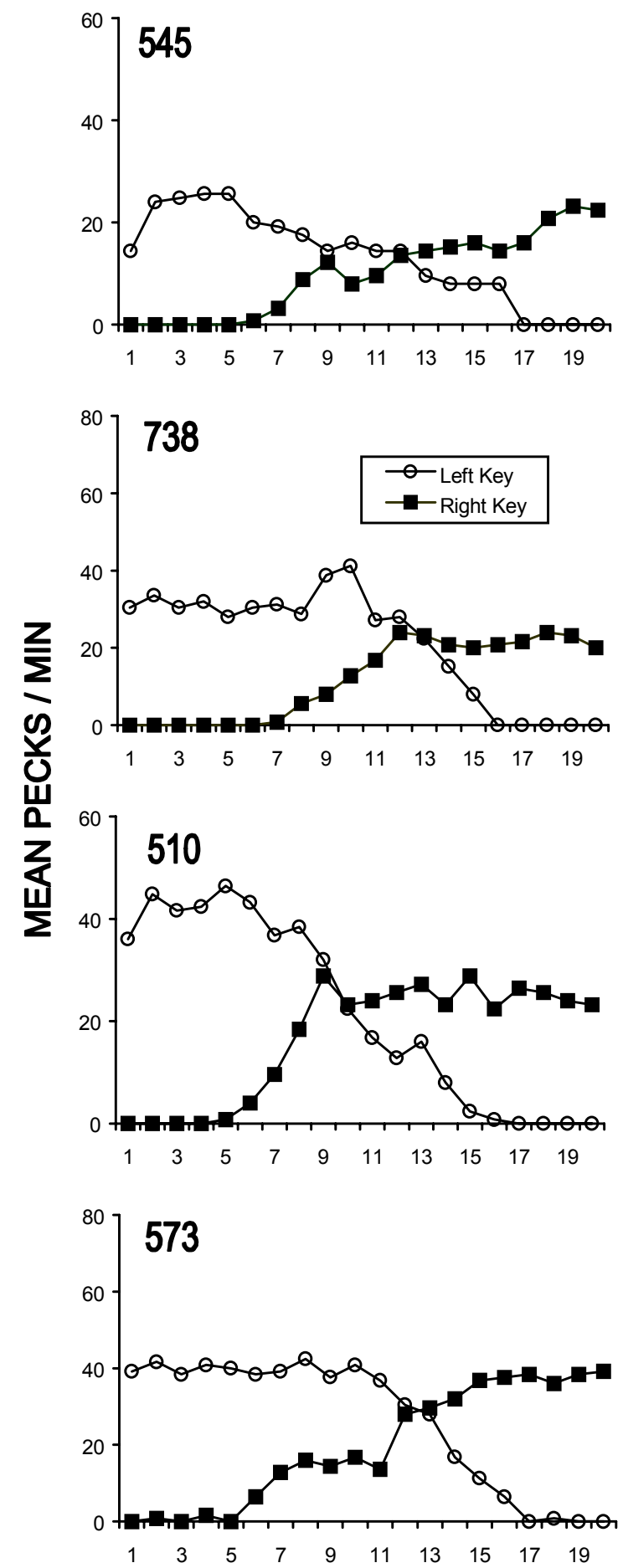

VI $30 \mathrm{~s}$
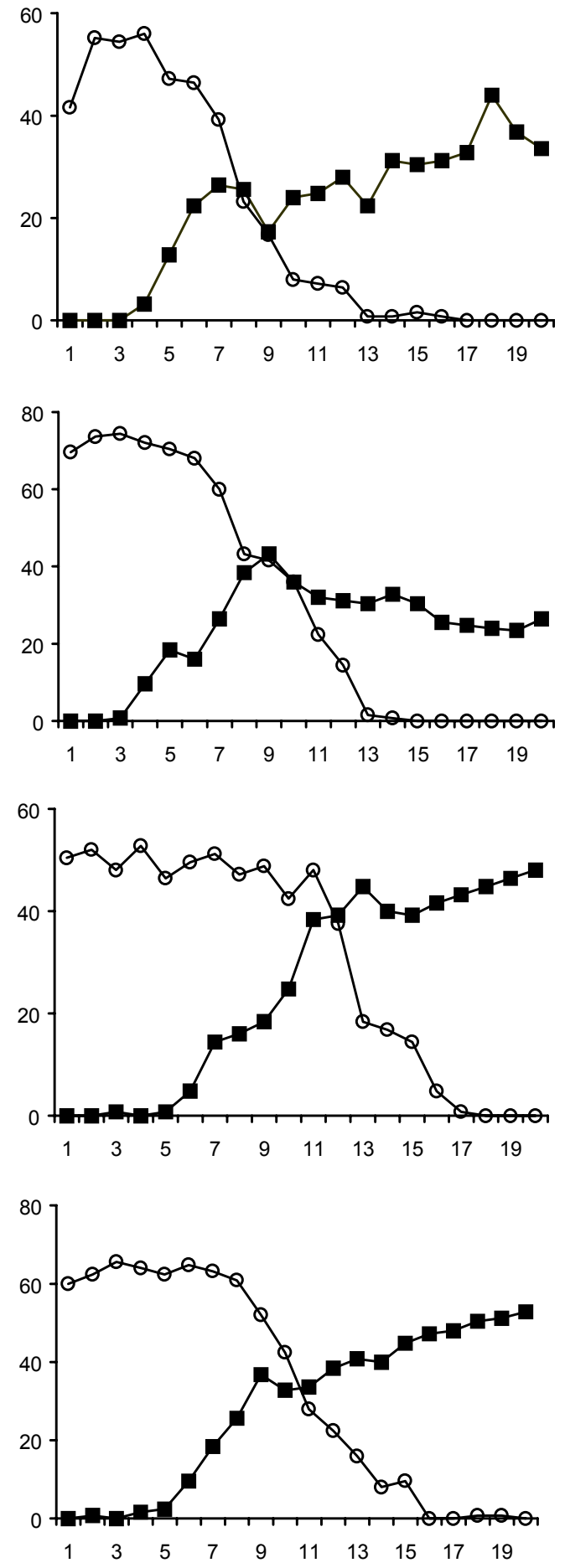

\section{5-s BINS}

Figure 1. Mean response rates (pecks/min) on left (open circles) and right keys (filled squares) during the VI 120-s component (left column) and the VI 30-s component (right column) across twenty 2.5-s bins of each trial for each pigeon. Each graph represents the mean of the last six sessions of the first baseline condition. Note: the y-axes are scaled differently for each pigeon. 
the right key were low during the early portions of the interval and then increased as the time in the interval elapsed. For three out of four pigeons $(545,738$, and 573$)$, left-key response rates began to decrease and right-key response rates began to increase earlier in the intervals in which responding was reinforced according to a VI 30-s schedule relative to when responding was reinforced according to a VI 120-s schedule (i.e., the left key response rate function and the right key response rate function cross one another at earlier points during the VI 30-s component than during the VI 120-s component). For pigeon 510, the opposite effect occurred in which response rates on the left key began to decrease and right-key response rates began to increase earlier when responding was reinforced according to a VI 120-s schedule relative to when responding was reinforced on a VI 30-s schedule. When the VI 120-s component was in effect, response rates on the left key were lower during the first 2.5 -s bin relative to the next five or six bins for Pigeons 545 and 510. A similar pattern was observed for Pigeons 545, 738, and 573 during the VI 30-s component. In addition, response rates on the right key during the last $25 \mathrm{~s}$ of the interval (i.e., the last 10 bins) tended to be lower than response rates on the left key during the first $25 \mathrm{~s}$ of the interval (i.e., the first 10 bins).

Similar effects are shown in Figure 2, where the proportion of right key pecks is shown as a function of 2.5-s bins of the interval during the VI 120-s component (open triangles) and the VI 30-s component (filled diamonds). The proportion of right key pecks was calculated by dividing the number of right key pecks in each bin by the total number of left and right key pecks in each bin. In general, the proportion of right key pecks was low during the early portion of the interval and increased as the time in the interval elapsed. For three out of four pigeons $(545,738$, and 573), the proportion of right key pecks began to increase earlier in the interval and approached 1.0 earlier in the VI 30-s component than during the VI 120-s component. For 

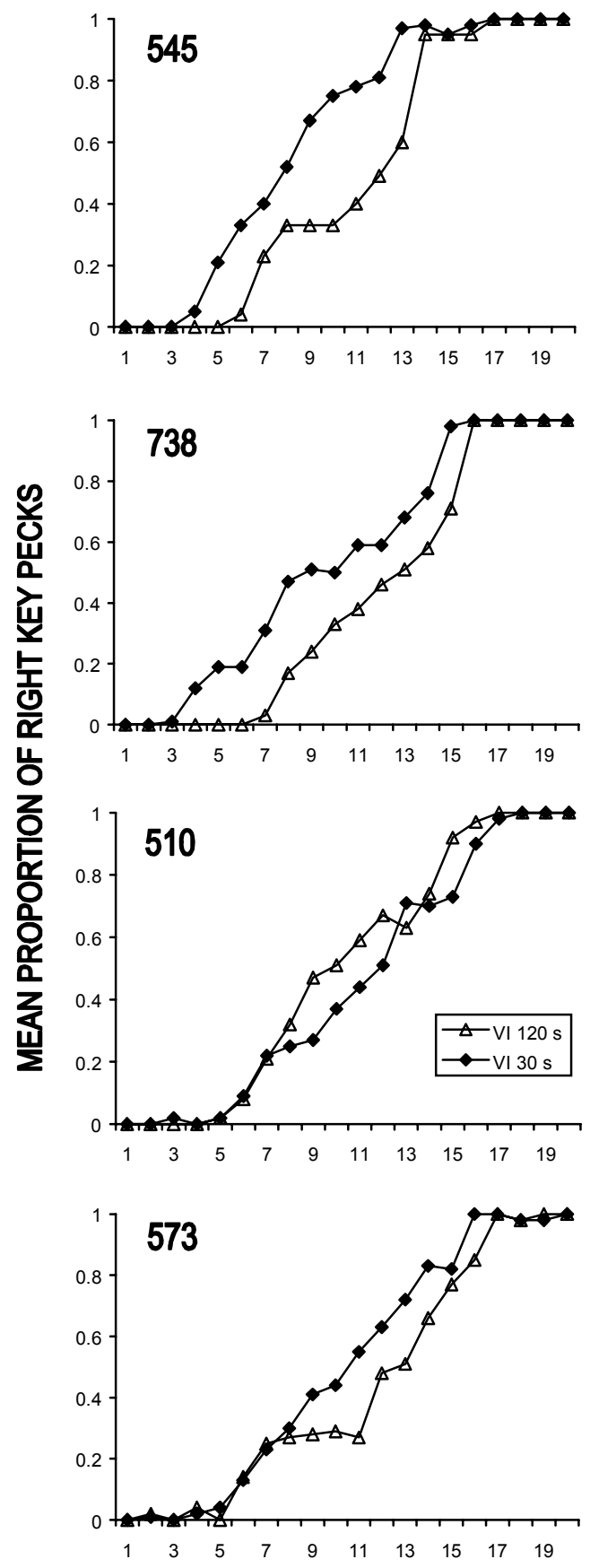

\section{5-S BINS}

Figure 2. Mean proportion of right key pecks (number of right key pecks / total number of pecks on left and right keys) across twenty 2.5 -s bins of each trial for each pigeon for responding during the VI 120-s component (open triangles) and the VI 30-s component (filled diamonds). Each graph represents the mean for the last six sessions of the first baseline condition. 
Pigeon 510, proportion of right key pecks increased earlier and reached 1.0 earlier during the VI 120-s component than during the VI 30-s component. The patterns of left- and right-key response rates and proportion of right key pecks did not vary greatly across conditions, unless shifts in the functions occurred, which are reflected in changes in the ET50 (see below). In addition, the slopes in the functions (i.e., variability) shifted with changes in the ET50. That is, when the ET50 decreased, variability also decreased and vice versa, consistent with Weber's law. There were no meaningful changes, however, when disruption tests were conducted. Therefore, the overall measures of response rates and ET50 will be discussed throughout the remainder of this section.

Figure 3 shows the mean (and standard deviation) response rates during the VI 120-s component (filled bars) and the VI 30-s component (dashed bars) during the last six sessions preceding each of the four disruption conditions for each pigeon. The data in Figures 3 and 4 are presented in the same order across pigeons, despite the fact that the conditions were conducted in a different order for each pigeon (see Table 1). Response rates were calculated by dividing the total left and right key pecks by the time the keys were lit across the entire session. In general, response rates were higher during the VI 30-s component than during the VI 120-s component. For Pigeon 545, response rates during the VI 30-s component were slightly lower on the sessions preceding the VT 5-s test condition and prefeeding than during the sessions preceding the VT 15- or 30-s test conditions. There was little change in response rates during the VI 120-s component across conditions for Pigeon 545. No systematic increases or decreases in response rates were observed for Pigeon 738. For Pigeon 510, response rates during the VI 30-s component were slightly lower during the sessions preceding prefeeding than during the sessions preceding the VT test conditions. Response rates did not change systematically during the VI 


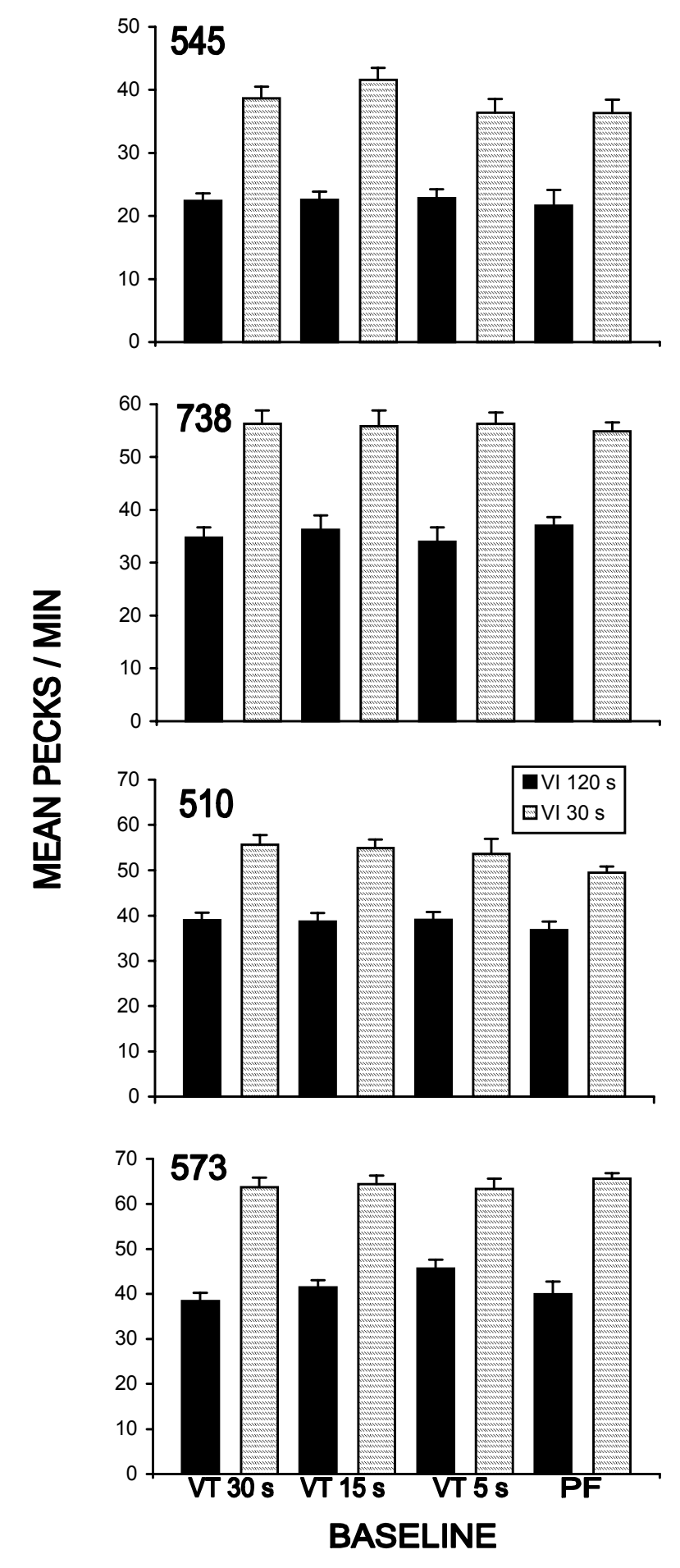

Figure 3. Mean (and standard deviation) response rates (pecks per minute) during the VI 120-s component (filled bars) and the VI 30-s component (dashed bars) during the last six sessions preceding each of the four disruption conditions for each pigeon. Note: the y-axes are scaled differently for each pigeon. 
120-s component for Pigeon 510. Finally, for Pigeon 573, response rates during the VI 30-s component were slightly higher during the sessions preceding the VT 5-s test condition than the other test conditions. Response rates during the VI 120-s component did not change systematically for Pigeon 573.

Figure 4 shows the mean (and standard deviation) ET50 during the VI 120-s component (filled bars) and the VI 30-s component (dashed bars) during the last six sessions preceding each of the four disruption conditions for each pigeon. Based on the proportion of right key peck data, the ET50 (i.e., the time at which $50 \%$ of responding occurred on the right key) was estimated through linear interpolation. The horizontal dashed line represents an ET50 of $25 \mathrm{~s}$, which would indicate that the switch from pecking the left key to pecking the right key occurred at the exact temporal midpoint of the trial. Values above the dashed line indicate switching later than $25 \mathrm{~s}$ (i.e., an underestimation of time) and values below the dashed line indicate switching earlier than 25 s (i.e., an overestimation of time). The ET50 tended to be higher during the VI 120-s component than during VI 30-s component across all of the pigeons, with one exception (see below). For pigeon 545, the ET50 did not vary systematically during the VI 120-s component. During the VI 30-s component, however, the ET50 decreased after the VT 30-s test condition and did not return to the original baseline levels for the remainder of the experiment. For Pigeon 738, the ET50 did not vary systematically across conditions, with the exception of a slight increase during the sessions preceding prefeeding. For Pigeon 510, the ET50 changed across baseline sessions. Prefeeding was the first disruptor tested for this pigeon (see Table 1), and is the baseline performance shown in Figures 1 and 2. Initially, the ET50 was higher during the VI 30-s component than during the VI 120-s component. During the sessions preceding the VT $30-\mathrm{s}$ test condition (Test 2, see Table 1), the ET50 was slightly higher than $25 \mathrm{~s}$ during the VI 120-s 

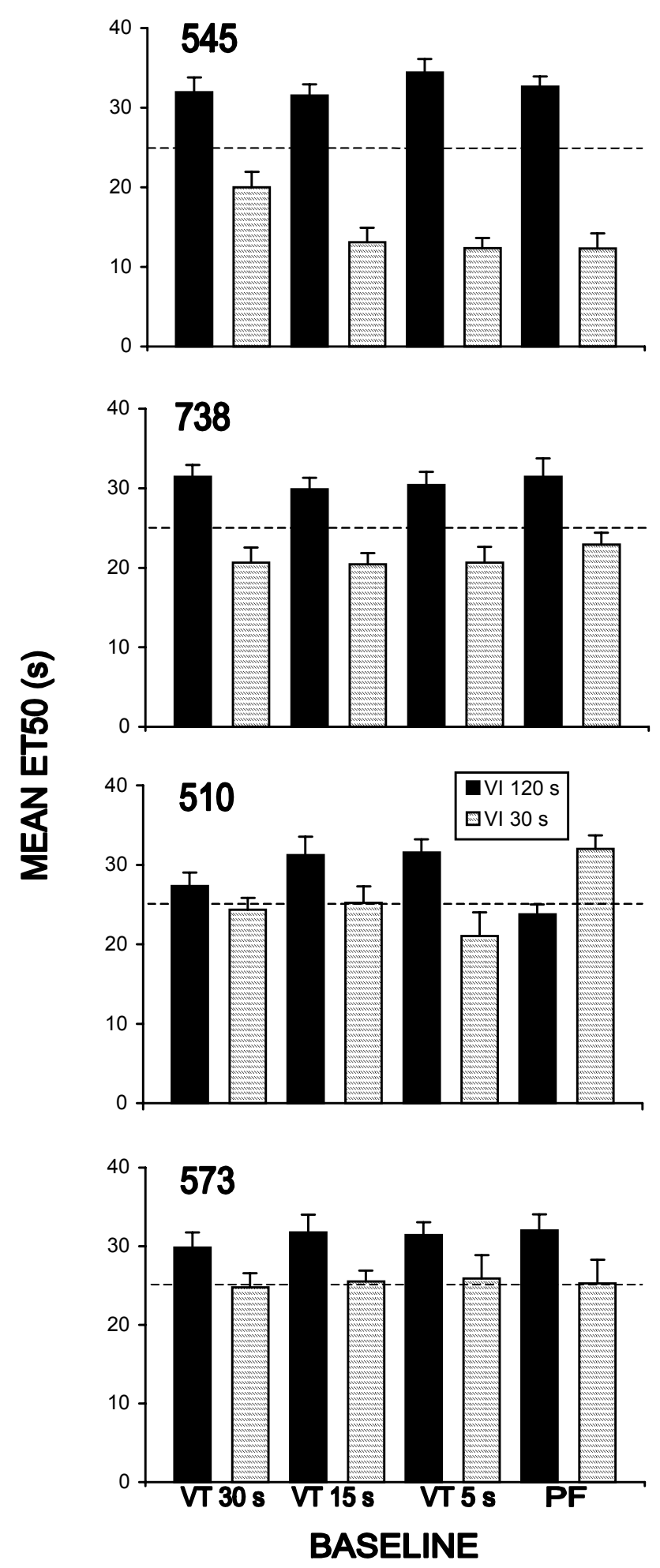

Figure 4. Mean (and standard deviation) ET50 (s) during the VI 120-s component (filled bars) and the VI 30-s component (dashed bars) during the last six sessions preceding each of the four disruption conditions for each pigeon. The horizontal dashed line indicates an ET50 of $25 \mathrm{~s}$. 
component and slightly lower than $25 \mathrm{~s}$ during the VI 30 -s component. These differences became more pronounced throughout the remainder of the test conditions (i.e., VT 15 and 5 s). No systematic differences in ET50 were observed across conditions for Pigeon 573.

Figure 5 shows the proportion of baseline response rates during the VI 120-s component (open triangles) and VI 30-s components (filled diamonds) during each VT 30-, 15-, and 5-s session for each pigeon. These data allow for a comparison of response rates (and ET50, see below) despite differences in absolute response rates (or ET50; Nevin, 1974). Proportions were calculated by dividing response rates in each component during each VT test session by the mean of the response rates from that component for the last six sessions preceding the test conditions. The horizontal line indicates a proportion of 1.0 or no change from baseline. Values above the line indicate an increase in response rates compared to baseline and values below the line indicate a decrease in response rates relative to baseline. In general, proportions tended to vary systematically in relation to the value of the VT schedule: proportions were lower when response-independent food was delivered according to a VT 5-s schedule than when delivered according to a VT 15- or 30-s schedule, despite the fact that test conditions were conducted in ascending order for Pigeons 545 and 510 and descending order for Pigeons 738 and 573. In addition, proportions tended to be lower during the VI 120-s component, with one exception (see below). For Pigeon 545, during the VT 30-s test condition, response rates initially decreased during the VI 30-s component and then increased above baseline levels. During the VI 120-s component, response rates decreased during the first session, then increased above baseline levels and then decreased to approximate baseline levels. During the VT 15-s test condition, response rates decreased as a function of test sessions and the decreases were slightly more pronounced during the VI 30-s component. During the VT 5-s test condition, response rates were 

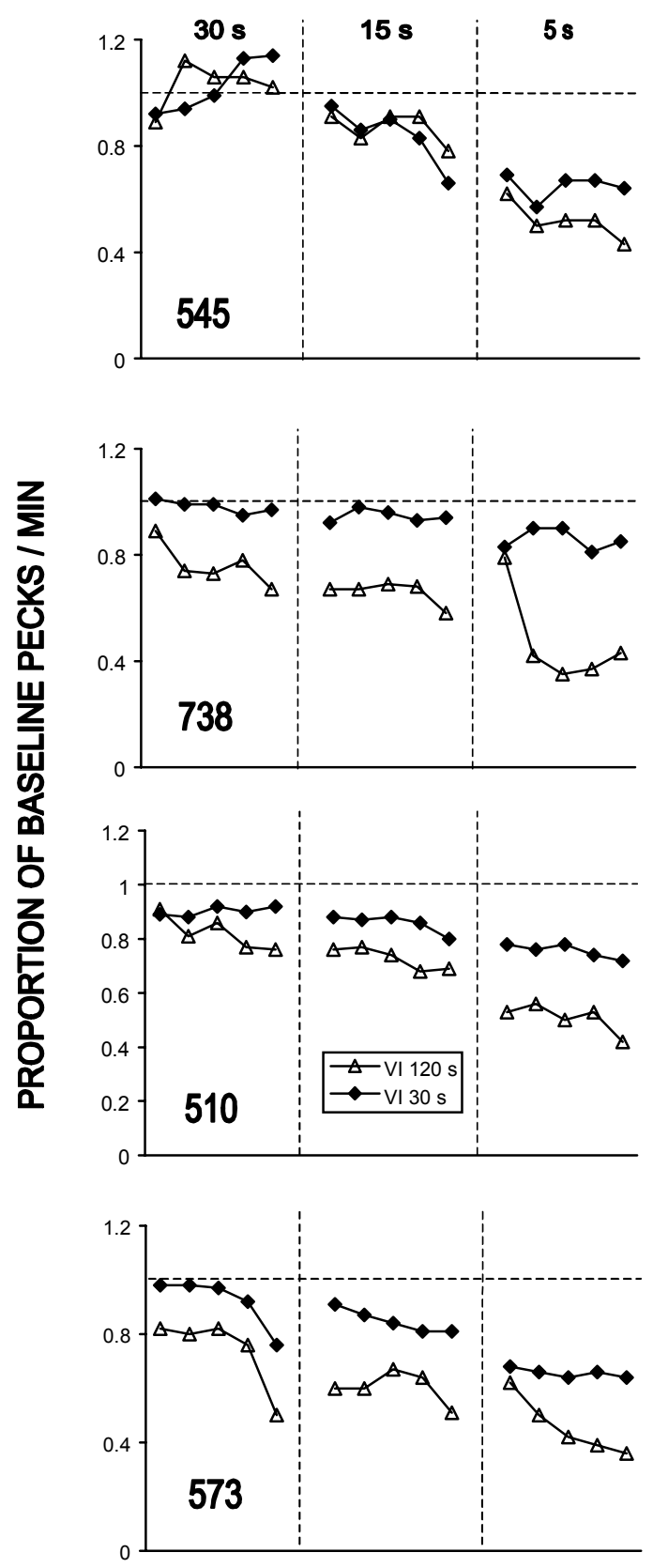

VT SESSIONS

Figure 5. Proportion of baseline response rates (pecks/min) during VI 120-s components (open triangles) and VI 30-s components (filled diamonds) during each VT 30-, 15-, and 5-s session for each pigeon. The horizontal line indicates a proportion of 1.0 or no change from baseline. 
decreased even further and these decreases were more pronounced during the VI 120-s component. For the remainder of the pigeons, response rate decreases were more pronounced during the VI 120-s component across all conditions than during the VI 30-s component.

Figure 6 shows the proportion of baseline ET50 during the VI 120-s components (open triangles) and VI 30-s components (filled diamonds) during each VT 30-, 15-, and 5-s sessions for each pigeon. Proportions were calculated in the same fashion as described above for response rates. The horizontal line indicates a proportion of 1.0 or no change from baseline. Values above the horizontal line indicate an increase from baseline and an underestimation of time (i.e., the switch from left to right key pecking occurred later in the interval) relative to baseline while values below the horizontal line indicate a decrease from baseline and an overestimation of time relative to baseline (i.e., the switch from left to right key pecking occurred earlier in the interval). For Pigeon 545, during the VT 30-s test condition, the ET50 increased, decreased, and then increased approximating baseline levels during the VI 120-s component. The ET50 decreased across test sessions during the VI 30-s component. During the VT 15-s test condition, the ET50 was higher during the VI 30-s component than during the VI 120-s component, with one exception: on the second session of testing, the ET50 was lower during the VI 30-s component than during the VI 120-s component. Finally, during the VT 5-s test condition, the ET50 decreased as function of test session during the VI 120-s component. The ET50 decreased, increased, and decreased below baseline levels during the VI 30-s component. The decreases were more pronounced during the VI 120 -s component than during the VI 30-s component. For Pigeon 738, during the VT 30-s test condition, the ET50 remained the same or was slightly decreased during the VI 120-s component, while it was increased above baseline during the VI 30-s component. During the VT 15-s test condition, the ET50 was lower during the VI 120-s 

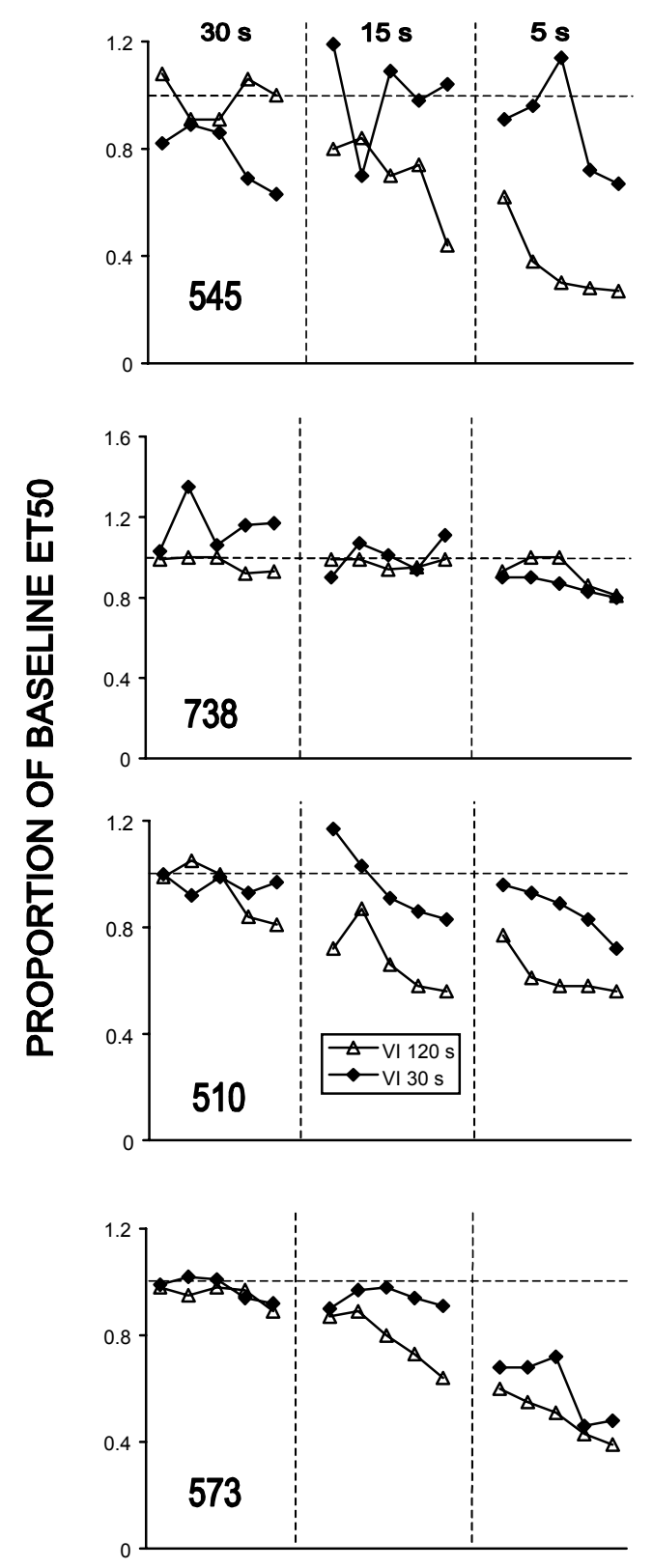

VT SESSIONS

Figure 6. Proportion of baseline ET50 during VI 120-s components (open triangles) and VI 30-s components (filled diamonds) during each VT 30-, 15-, and 5-s session for each pigeon. The horizontal line indicates a proportion of 1.0 or no change from baseline. Note: the $y$-axis is scaled differently for Pigeon 738. 
component on three out of the five test sessions. During the VT 5-s test condition, the ET50 during the VI 30-s component was either the same as or lower than the ET50 during the VI 120-s component. For Pigeon 510, the ET50 during the VI 30-s component was either the same as or slightly lower than baseline levels during the VI 30-s component. During the VI 120-s component, the ET50 initially increased but during the last two sessions of testing decreased below baseline levels during the VT 30-s test condition. During the VT 15- and 5-s test conditions, the ET50 was, in most cases, decreased below baseline levels and these decreased were more pronounced during the VI 120-s component. For Pigeon 573, the ET50 during the VI 120-s component was lower than during the VI 30-s component, and these differences were more pronounced as the amount of response-independent food was increased. In summary, in seven of the 12 test conditions conducted across all of the pigeons (i.e., three test conditions for four pigeons), the ET50 was clearly more disrupted (i.e., decreases were more pronounced) during the VI 120-s component than during the VI 30-s component. In three of 12 test conditions, the ET50 during the VI 120-s component was only slightly more disrupted than the VI 30-s component. Finally, in two of the 12 conditions, the ET50 was more disrupted during the VI 30-s component than during the VI120-s component. In addition, when the ET50 was disrupted, on most occasions it was decreased, rather than increased.

Figure 7 shows the proportion of baseline response rates during VI 120-s components (open triangles) and VI 30-s components (filled diamonds) during each prefeeding session for each pigeon. The horizontal line indicates a proportion of 1.0 or no change from baseline. In general, response rates were not systematically increased or decreased across sessions until responding was eliminated during the final prefeeding session (see Table 1 for the largest amount of food given and consumed during prefeeding test conditions). For Pigeon 545, response rates 

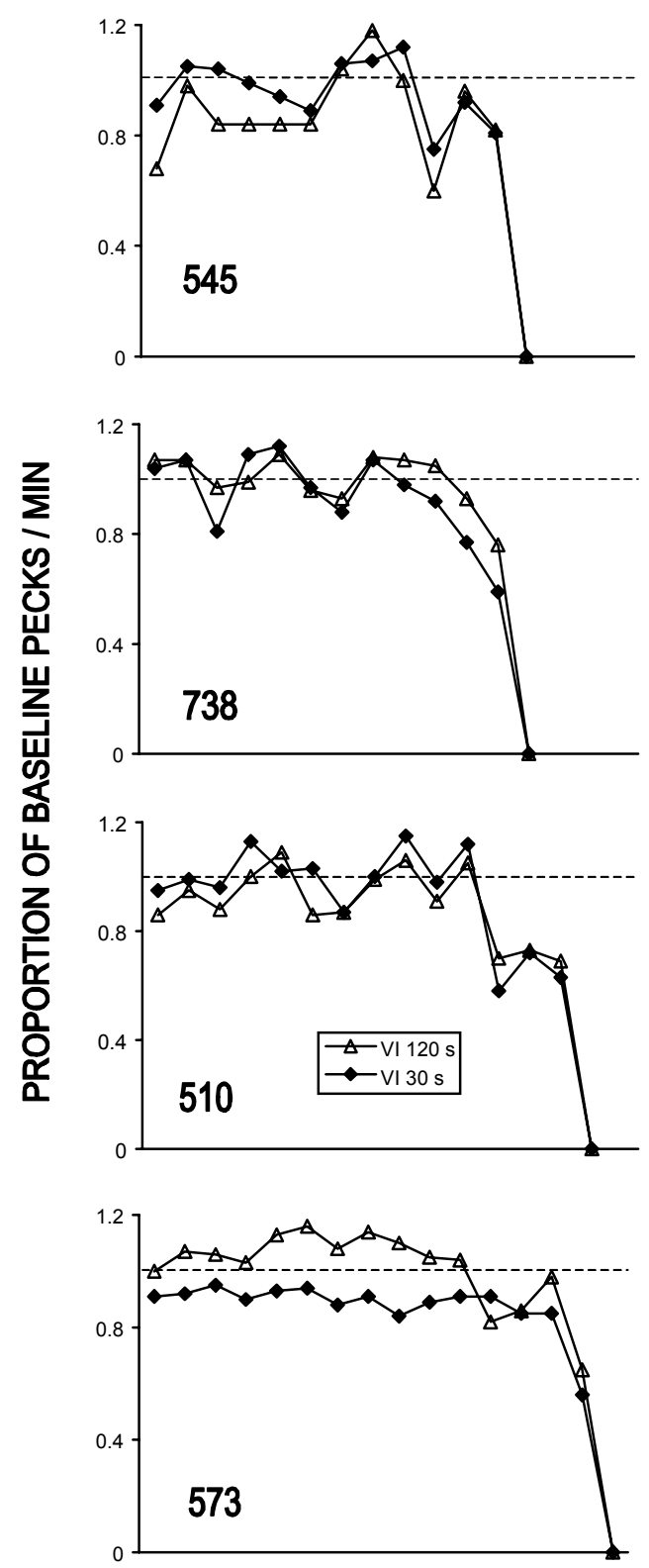

PREFEEDING SESSIONS

Figure 7. Proportion of baseline response rates (pecks/min) during VI 120-s components (open triangles) and VI 30-s components (filled diamonds) during each prefeeding session for each pigeon. The horizontal line indicates a proportion of 1.0 or no change from baseline. 
were slightly increased or decreased over the first six sessions of prefeeding, and decreases were more pronounced during the VI 120-s component. Response rates were then either increased or decreased until responding was eliminated. During most sessions, response rates were slightly more disrupted during the VI 120-s component. For Pigeon 738, response rates did not vary systematically until the four sessions before responding was eliminated. During these sessions, response rates were decreased and the decreases were more pronounced during the VI 30-s component. For Pigeon 510, response rates were not systemically affected. During eight of the 15 test sessions, response rates were slightly more disrupted during the VI 120-s component. For Pigeon 573, across most of the prefeeding sessions, response rates were increased during the VI 120-s component and decreased during the VI 30-s component.

Figure 8 shows the proportion of baseline ET50 during VI 120-s components (open triangles) and VI 30-s components (filled diamonds) during each prefeeding session for each pigeon. The horizontal line indicates a proportion of 1.0 or no change from baseline. In general, the ET50 during the VI 30-s component was increased above or remained the same as baseline. The ET50 during the VI 120-s component was decreased below or remained the same as baseline. Thus, in most cases, the ET50 was lower during VI 120-s component than during the VI 30-s component. With the exception of Pigeon 545 and the last three prefeeding sessions for Pigeon 738, the changes in ET50 were relatively small and slightly more pronounced during the VI 30-s component. Thus, on most sessions, prefeeding produced underestimations of time during the VI 30-s component and overestimations of time during the VI 120-s component.

\section{Discussion}

The results from Experiment 1 were consistent with other experiments using the FOPP: response rates on the left key were high during the early part of the intervals and then decreased 


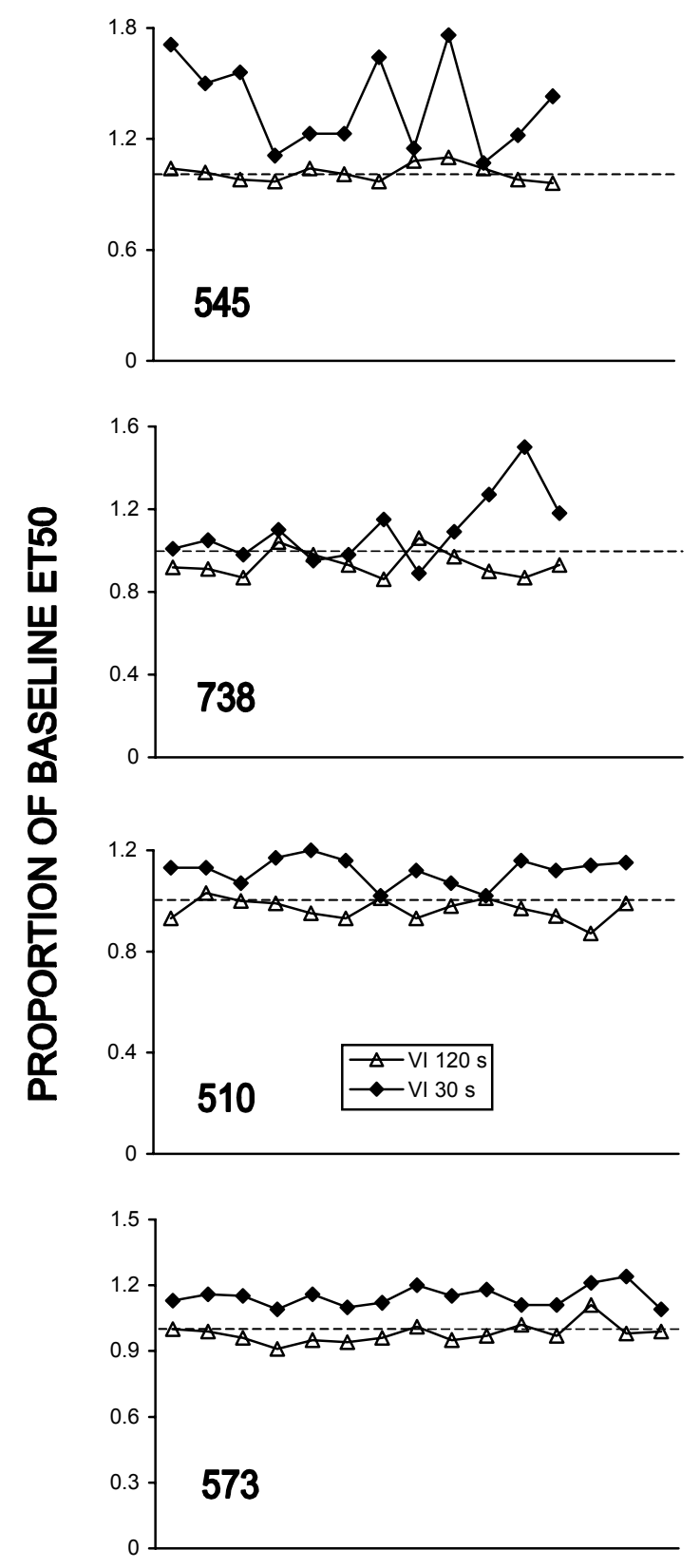

PREFEEDING SESSIONS

Figure 8. Proportion of baseline ET50 during VI 120-s components (open triangles) and VI 30-s components (filled diamonds) during each prefeeding session for each pigeon. The horizontal line indicates a proportion of 1.0 or no change from baseline. Note: the y-axes are scaled differently for each pigeon. 
to low or zero rates, while response rates on the right key were low during the early portions of the intervals and then increased to high rates for the remainder of the intervals. In addition, the proportion of right key pecks were low during the early portions of the intervals and then increased to asymptotic levels during the second portion of the intervals (Bizo \& White, 1994a, 1994b; Stubbs, 1968, 1979, 1980). There also was a systematic difference in baseline performance in ET50 between the lean and rich components of the multiple schedule that was consistent with the BeT: when responding was maintained by a higher rate of reinforcement, the ET50 was usually lower than the component with a lower rate of reinforcement, consistent with an overestimation of time, which replicates the findings of Grace and Nevin (2000).

There were, however, several cases in which order effects may be evident. For example, the first test condition conducted for Pigeon 545 was the VT 30-s schedule. During this condition, the ET50 during the VI 120-s component was either increased or only slightly decreased below baseline (See Figure 6). The ET50 during the VI 30-s component, conversely, was decreased to a little over half of the baseline ET50. After the first test condition, the ET50 did not return to the original baseline level during the VI 30-s component (see Figure 4). Although this performance was stable throughout the remainder of the experiment, a comparison of the variability in the ET50 data for Pigeon 545 during the remainder of the experimental conditions (VT 15- and 5-s and prefeeding conditions) and the variability in the ET50 data for the other pigeons shows that performance was less stable for this particular pigeon. In addition, the ET50 during the VI 120-s component only was disrupted more than the VI 30-s component on those occasions when the baseline differences in ET50 were more extreme (see Figure 6 and 8). Finally, marked increases in the ET50 were observed during the VI 30-s component during both the remainder of the VT test conditions and prefeeding. The size of the increases or the fact 
that increases occurred at all may be due to floor effects on the ET50. During the VI 30-s component, the ET50 was often between 12 and $15 \mathrm{~s}$. Switching to the right key even sooner would mean that at least $15 \mathrm{~s}$ of the 50 -s trial would be spent pecking a key that would never produce reinforcement. Although switching to the right key sooner would be consistent with the $\mathrm{BeT}$, switching to the right key later produced more access to reinforcement.

There also seemed to be an order effect in the ET50 data for Pigeon 738 during the VT test conditions (see Figure 6). For this particular pigeon, the VT test conditions were conducted first and the schedules were tested in descending order (i.e., VT 5-, 15-, and then 30-s test conditions). It is worth noting that initially the ET50 during the VI 30-s component was more disrupted during the first test condition (i.e., VT $5 \mathrm{~s}$ ) and then during the remainder of the VT test conditions, the ET50 during the VI 120-s component was more disrupted than during the VI 30-s component. These effects are only evident in the ET50 data. Finally, for Pigeon 510, the baseline ET50 during the VI 30-s component shifted throughout the experiment. For this pigeon, the first test conducted was prefeeding and the baseline ET50 was higher during the VI 30-s component (see Table 1 and Figure 4) than during the VI 120-s component. For the remainder of the test conditions, the baselines shifted in a manner that was consistent with the data from the other pigeons, in that the baseline ET50 was lower during the VI 30-s component than during the VI 120-s component.

It may be the case that after repeated exposure to the baseline or testing conditions, the ET50 recalibrated or adjusted (Killeen \& Fetterman, 1988). This possibility will be discussed in more detail in the General Discussion, but the BeT assumes that when changes in reinforcement rate produce changes in the pacemaker rate (reflected in changes of the ET50), a corresponding change will occur in the behavioral states associated with timing. For example, if the rate of the 
pacemaker is increased, an organism will arrive in the final behavioral state sooner (i.e., overestimation of time will occur). To maintain accurate performance, new behavior becomes correlated with the later states and then serves as a cue for timing. Many researchers predict that changes in reinforcement rate will not produce lasting changes on the ET50 based on this assumption (Bizo \& White, 1994a; Haight \& Killeen, 1991; Killeen \& Fetterman, 1988; Morgan, Killeen, \& Fetterman, 1993). After exposure to the first test condition for Pigeon 545 when the ET50 during the VI 30-s component was decreased, the pacemaker rate perhaps recalibrated and the resulting behavioral patterns persisted throughout the remainder of the experiment, although it is not clear why recalibration occurred only during the VI 30-s component. Likewise, for Pigeons 738 and 510, perhaps because of repeated exposure to the baseline and testing conditions, baseline or test performance shifted, accommodating new behavioral patterns.

Thus, the results from the VT test conditions of the present experiment seem to replicate and extend the findings of Grace and Nevin (2000). Grace and Nevin (2000) used a peak procedure and manipulated overall rate of reinforcement by using two different FI values. Due to the scalar property of timing, the larger disruption of behavior during the lean component may have been due to lower levels of stimulus control rather than lower rates of reinforcement. The present experiment used the FOPP, which allowed the reinforcement rate to be manipulated without altering the temporal integrity of the procedure. In addition, Grace and Nevin (2000) only tested one VT value (VT 7.5-s schedule), therefore the present experiment extends the findings of Grace and Nevin (2000) by testing a range of VT values and finding that, in most cases, the level of disruption was a function of the value of the VT. Grace and Nevin (2000) also found slight increases in the peak time during the component with the rich rate of reinforcement. 
Finally, any interpretation of the prefeeding data should be tentative in that no large systematic differences were observed between response rates during the VI 30-s and VI 120-s components. The ET50 during the VI 30-s component, however, was often more resistant to the disruptive effects of prefeeding than during the VI 120-s component. On most occasions, the ET50 during the VI 120-s component was reduced below baseline, while the ET50 during the VI 30-s component was increased above baseline. Therefore, although the data from the VT test conditions seem to replicate those found by Grace and Nevin (2000), the prefeeding data are not as compelling. Grace and Nevin (2000), however, only tested prefeeding amounts of 20, 40, and $60 \mathrm{~g}$. Even if the functions in the present experiment are truncated to only include the largest amounts of prefeeding (i.e., $22.5 \mathrm{~g}$ and above), the results are still not completely consistent with Grace and Nevin (2000). This effect will be discussed in more detail in the General Discussion.

\section{Experiment 2: Effects of Reinforcer Duration}

\section{Procedure}

FOPP Training.

Responding in the presence of green keys was reinforced by 1-s access to grain.

Responding in the presence of the red keys was reinforced by 6.5 -s access to grain. The VI scheduled was increased in 15-s increments over the course of several sessions until reaching the terminal value of a VI 60-s schedule.

\section{Disruptors.}

Table 2 shows the order of conditions and the number of sessions in each condition. For two pigeons (858 and 778), the first disruptor was the delivery of response-independent food during the 15-s ITI. For the other two pigeons (562 and 553), the order of disruptor test sessions was reversed so that the first disruptor test was prefeeding and the second was VT food delivery. 
Table 2.

Order of conditions, number of sessions for baseline and test conditions, and the largest amount of food given during prefeeding (PF; and consumed during prefeeding (g)), for each pigeon in Experiment 2.

\begin{tabular}{|c|c|c|c|c|c|c|c|c|c|c|}
\hline \multirow{3}{*}{$\begin{array}{l}\text { Condition } \\
\text { Baseline }\end{array}$} & \multicolumn{2}{|c|}{ Pigeon 858} & \multicolumn{2}{|c|}{ Pigeon 778} & \multicolumn{3}{|c|}{ Pigeon 562} & \multicolumn{3}{|c|}{ Pigeon 553} \\
\hline & Order & Sessions PF amt. & Order & Sessions PF amt. & Order & Session & is PF amt. & Order & Sessions & s PF amt. \\
\hline & & 74 & & 24 & & 33 & & & 16 & \\
\hline VT $30 \mathrm{~s}$ & 1 & 5 & 3 & 5 & 2 & 5 & & 4 & 5 & \\
\hline Baseline & & 36 & & 38 & & 21 & & & 28 & \\
\hline VT $15 \mathrm{~s}$ & 2 & 5 & 2 & 5 & 3 & 5 & & 3 & 5 & \\
\hline Baseline & & 19 & & 65 & & 17 & & & 29 & \\
\hline VT 5s & 3 & 5 & 1 & 5 & 4 & 5 & & 2 & 5 & \\
\hline Baseline & & 15 & & 19 & & 62 & & & 65 & \\
\hline Prefeeding & 4 & $22.5(22)$ & 4 & $42.5(35.6)$ & 1 & 15 & $82.5(34.9)$ & 1 & 16 & $42.5(42.5)$ \\
\hline
\end{tabular}


For two pigeons (858 and 562), the VT tests were conducted in ascending order (VT 30, 15, and $5 \mathrm{~s}$ ) while VT tests were conducted in descending order (VT 5, 15, and $30 \mathrm{~s}$ ) for the other two pigeons (778 and 553).

Results

Figure 9 shows mean response rates (pecks/min) on left (open circles) and right keys (filled squares) during the 1-s food component (left column) and the 6.5-s food component (right column) across twenty 2.5-s bins of each trial for each pigeon. Each graph represents the mean of the last six sessions of the first baseline condition. In general, response rates tended to be higher during the 1-s food component than during the 6.5-s food component across all pigeons. For all conditions and pigeons, response rates on the left key were highest during the early portions of the 50-s interval and decreased later in the interval to zero or near-zero rates. Response rates on the right key were low during the early portions of the interval and then increased as the time in the interval elapsed. For all of the pigeons, left-key response rates began to decrease and rightkey response rates began to increase earlier in the intervals in which responding was reinforced with 6.5-s access to food relative to when responding was reinforced with 1-s access to food (i.e., the left key response rate function and the right key response rate function cross one another at earlier points during the 1-s food component than during the 6.5-s food component). When the 6.5-s food component was in effect, response rates on the left key were lower during the first 2.5s bin relative to the next five or six bins for Pigeons 858 and 553. In addition, response rates on the right key during the last $25 \mathrm{~s}$ of the interval (i.e., the last 10 bins) tended to be lower than response rates on the left key during the first $25 \mathrm{~s}$ of the interval (i.e., the first 10 bins).

Similar effects are shown in Figure 10, where the proportion of right key pecks is shown as a function of 2.5-s bins of the interval during the 1-s food component (open triangles) and the 
1-s Food
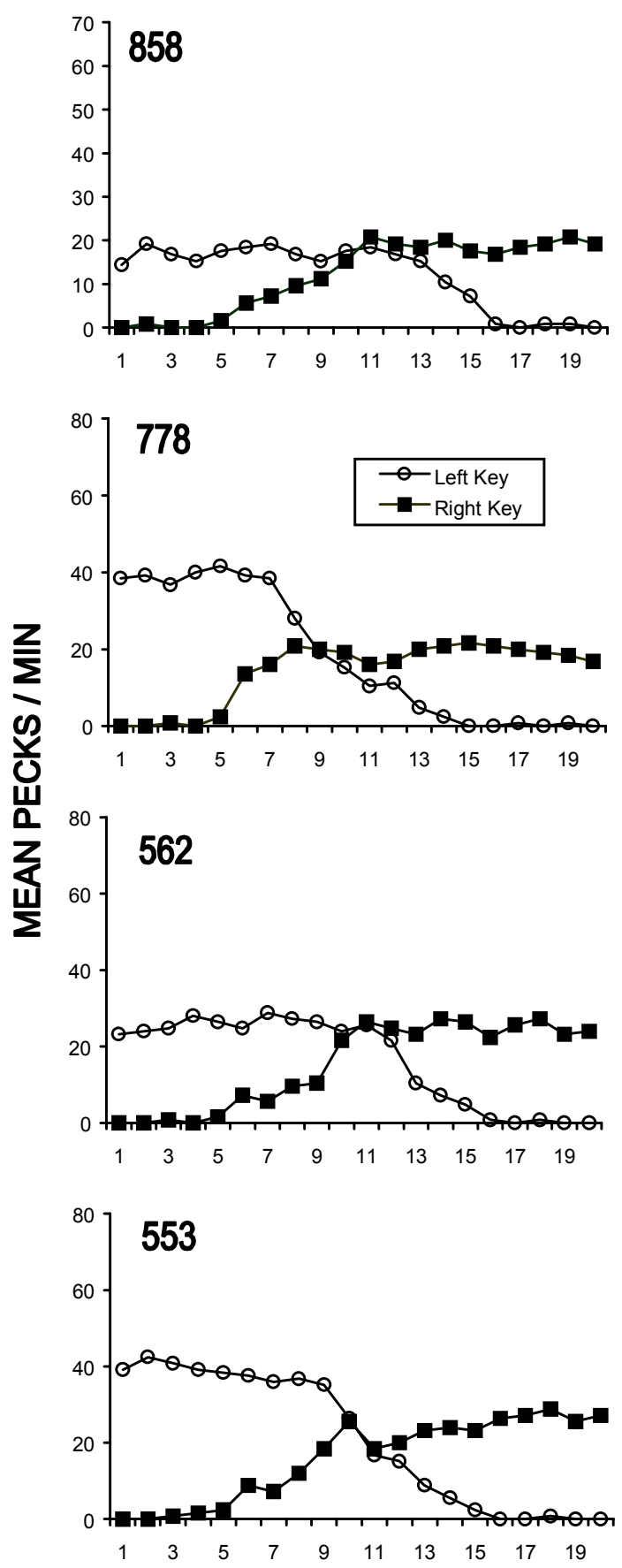

6.5-s Food
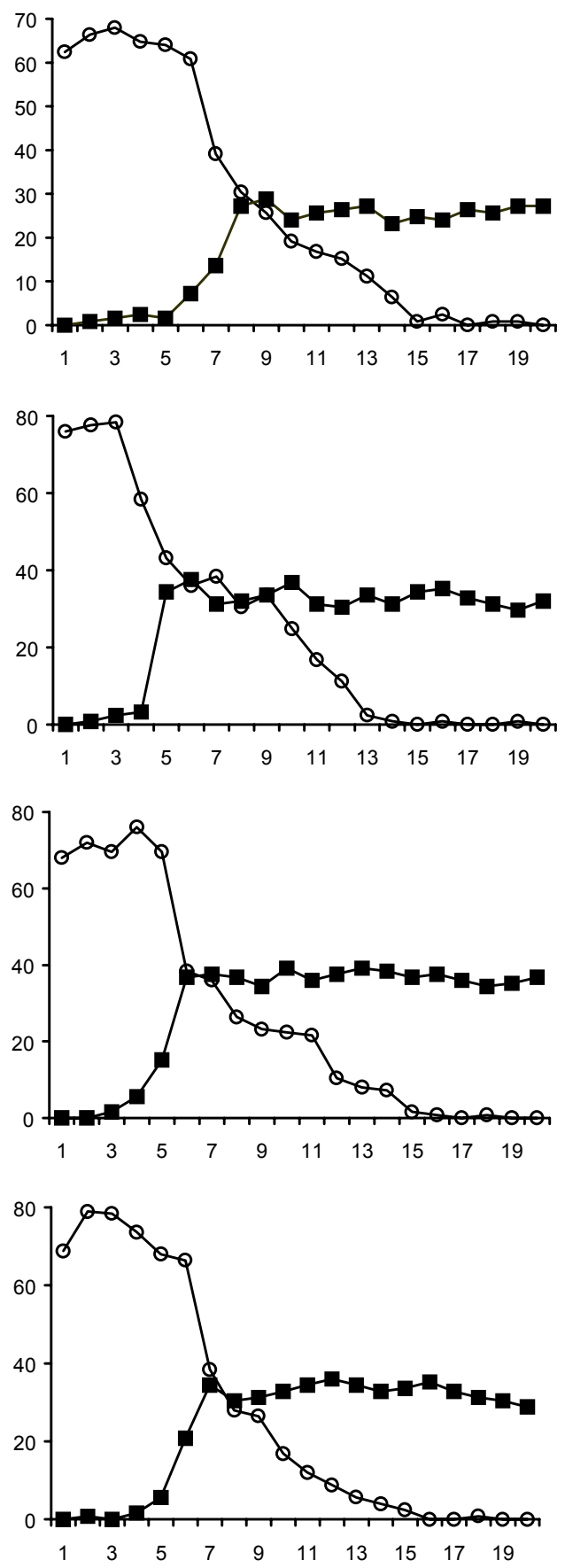

\section{5-s BINS}

Figure 9. Mean response rates (pecks/min) on left (open circles) and right keys (filled squares) during the 1-s food component (left column) and the 6.5-s food component (right column) across twenty 2.5-s bins of each trial for each pigeon. Each graph represents the mean of the last six sessions of the first baseline condition. Note: the y-axis is scaled differently for Pigeon 858 . 

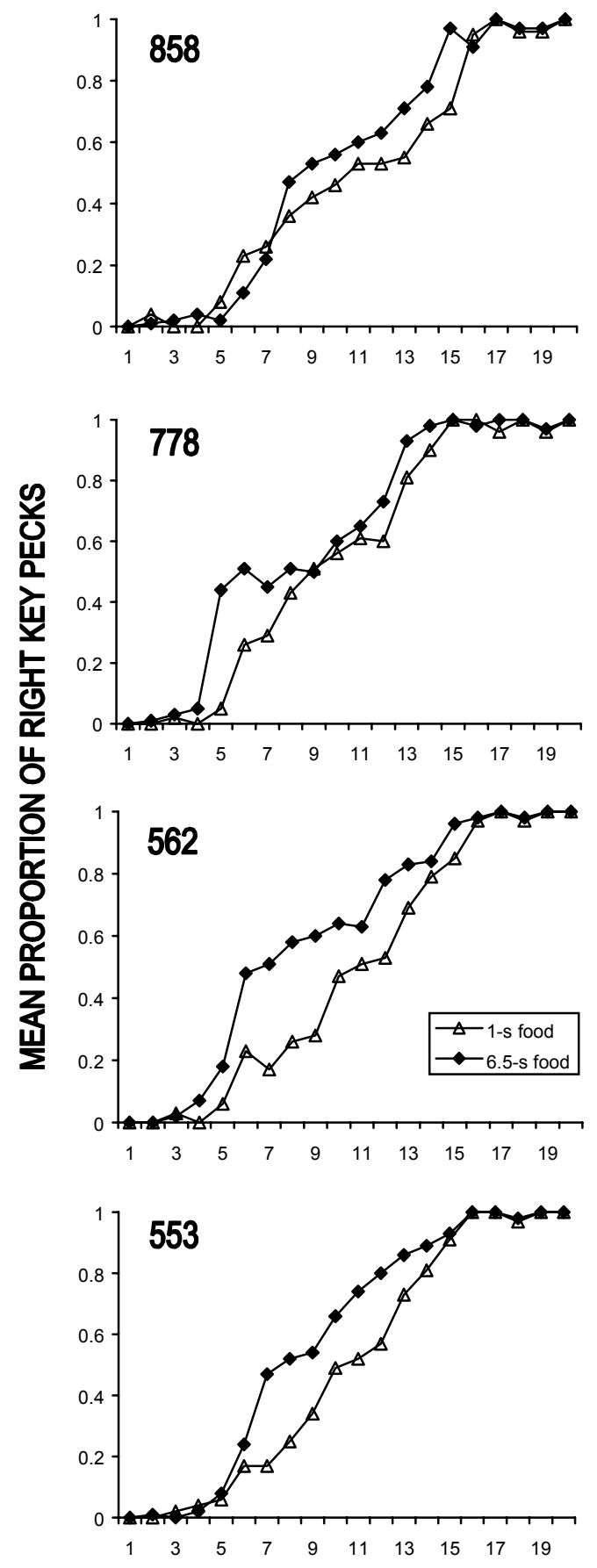

2.5-s BINS

Figure 10. Mean proportion of right key pecks (number of right key pecks / total number of key pecks on left and right keys) across twenty 2.5-s bins of each trial for each pigeon for responding during the 1-s food component (open triangles) and the 6.5-s food component (filled diamonds). Each graph represents the mean for the last six sessions of the first baseline condition. 
6.5-s food component (filled diamonds). In general, the proportion of right key pecks was low during the early portion of the interval and increased as the time in the interval elapsed. The proportion of right key pecks began to increase earlier in the interval and approached 1.0 earlier in the 6.5-s food component than during the 1-s food component. The patterns of left- and rightkey response rates and proportion of right key pecks did not vary greatly across conditions, unless shifts in the functions occurred, which are reflected in changes in the ET50. In addition, the slopes in the functions (i.e., variability) shifted with changes in the ET50. That is, when the ET50 decreased, variability also decreased and vice versa, consistent with Weber's law. There were no meaningful changes, however, when disruption tests were conducted. Therefore, the overall measures of response rates and ET50 will be discussed throughout the remainder of this section.

Figure 11 shows the mean (and standard deviation) response rates during the 1-s food component (filled bars) and the 6.5-s food component (dashed bars) during the last six sessions preceding each of the four disruption conditions for each pigeon. The data in Figures 11 and 12 are presented in the same order across pigeons, despite the fact that the conditions were conducted in a different order for each pigeon (see Table 2). Response rates were higher during the 6.5-s food component than during the 1-s food component. No systematic increases or decreases in response rates were observed for any of the pigeons, with one exception. For Pigeon 553 , response rates during the 1 -s food component were slightly higher during the sessions preceding prefeeding than during the sessions preceding the VT test conditions.

Figure 12 shows the mean (and standard deviation) ET50 during the 1-s food component (filled bars) and the 6.5-s food component (dashed bars) during the last six sessions preceding each of the four disruption conditions for each pigeon. The ET50 tended to be higher during the 

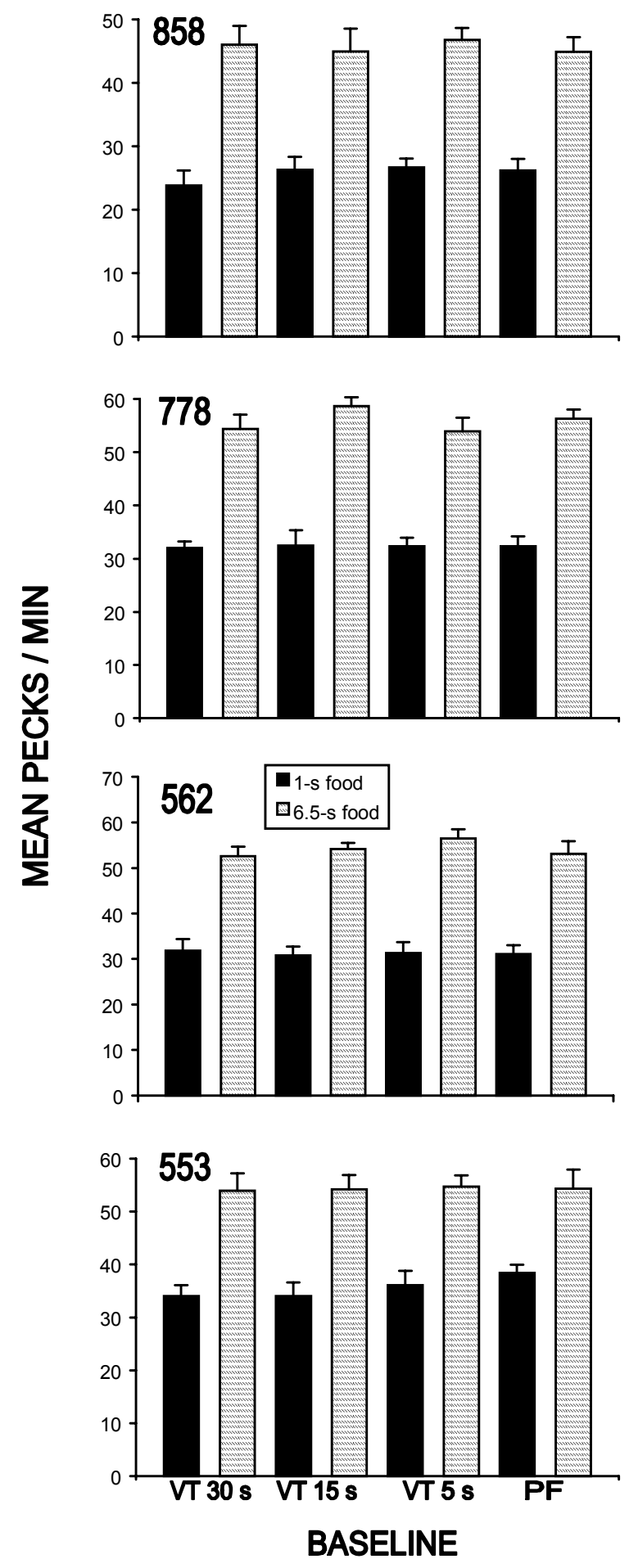

Figure 11. Mean (and standard deviation) response rates (pecks per minute) during the 1-s food component (filled bars) and the 6.5-s food component (dashed bars) during the last six sessions preceding each of the four disruption conditions for each pigeon. Note: the y-axes are scaled differently for each pigeon. 

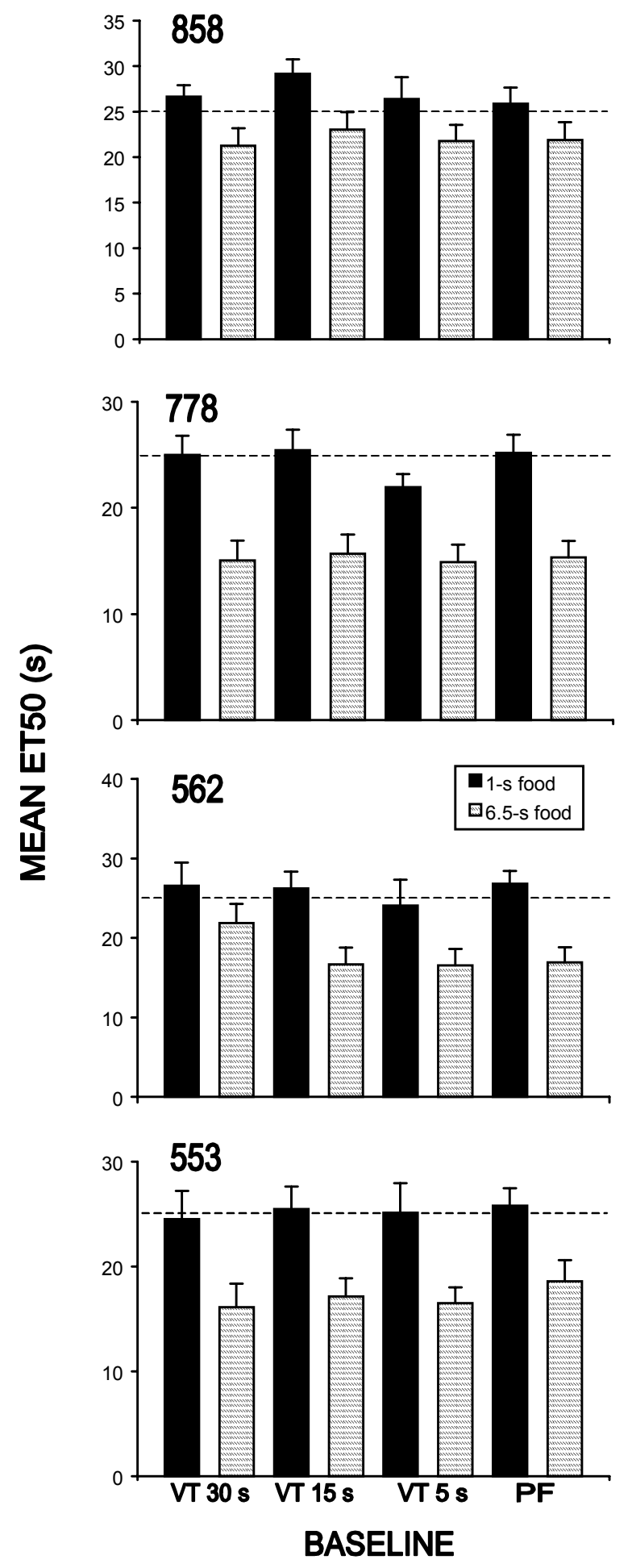

Figure 12. Mean (and standard deviation) ET50 (s) during the 1-s food component (filled bars) and the 6.5-s food component (dashed bars) during the last six sessions preceding each of the four disruption conditions for each pigeon. The horizontal dashed line indicates an ET50 of $25 \mathrm{~s}$. Note: the y-axes are scaled differently for each pigeon. 
1-s food component than during 6.5-s food component across all of the pigeons. For pigeon 858, the ET50 did not vary systematically during the 1-s food component. During the 6.5 -s food component, however, the ET50 was slightly higher during the sessions preceding the VT 15-s test conditions than during the other test conditions. For Pigeon 778, the ET50 during the 1-s food component was slightly lower during the sessions preceding the VT 5-s test condition than during the other test sessions. The ET50 did not vary systematically during the 6.5-s food component. For Pigeon 562, the ET50 during the 6.5-s food component changed across baseline sessions. Prefeeding was the first disruptor tested for this pigeon (see Table 2), and was followed by the VT 30-s test condition. During the sessions preceding the VT 30-s test condition, the ET50 was higher relative to the sessions preceding prefeeding, but returned to comparable levels during the sessions preceding the VT 15- and 5-s test conditions. No systematic differences in ET50 were observed across conditions for Pigeon 553.

Figure 13 shows the proportion of baseline response rates during the 1-s food component (open triangles) and 6.5-s food components (filled diamonds) during each VT 30-, 15, and 5-s session for each pigeon. The horizontal line indicates a proportion of 1.0 or no change from baseline. In general, proportions tended to vary systematically in relation to the value of the VT schedule: proportions were lower when response-independent food was delivered according to a VT 5-s schedule than when delivered according to a VT 15- or 30-s schedule, despite the fact that test conditions were conducted in ascending order for Pigeons 858 and 562 and descending order for Pigeons 778 and 553. In addition, proportions tended to be lower during the 1-s food component, with a few exceptions (see below). For Pigeon 858, during the VT 30-s test condition, response rates decreased slightly, remained the same or increased above baseline levels. During the VT 15-s test condition, response rates were initially decreased during the 6.5-s 

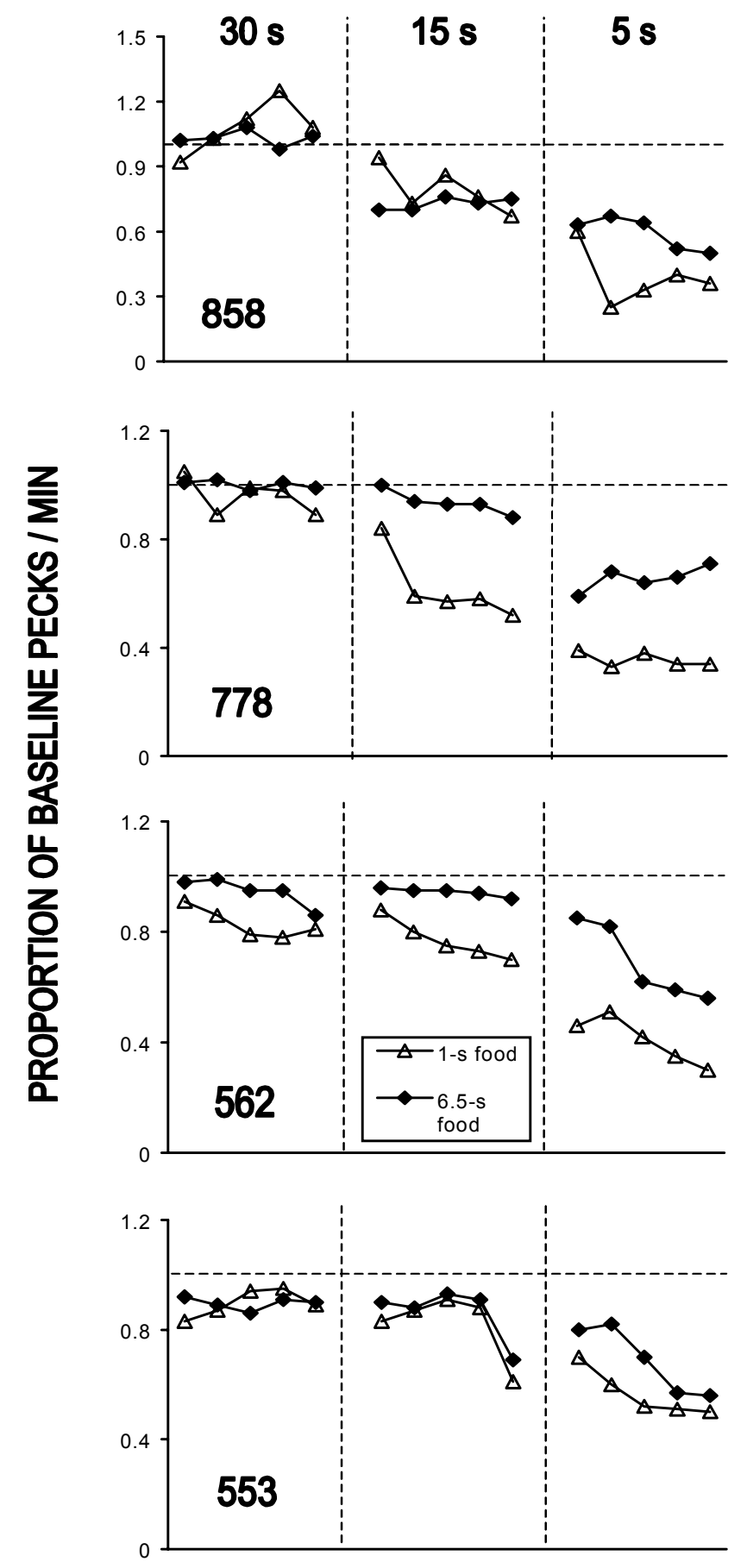

VT SESSIONS

Figure 13. Proportion of baseline response rates (pecks/min) during 1-s food components (open triangles) and 6.5-s food components (filled diamonds) during each VT 30-, 15-, and 5-s session for each pigeon. The horizontal line indicates a proportion of 1.0 or no change from baseline. Note: the y-axis is scaled differently for Pigeon 858 . 
food component, but did not change systematically across test sessions. During the 1-s food component, response rates decreased as a function of test sessions and the decreases were slightly more pronounced during the last test session during the 1-s food component. During the VT 5-s test condition, response rates were decreased even further and these decreases were more pronounced during the 1-s food component. For Pigeons 778 and 562, response rate decreases were more pronounced during the 1-s food component across all conditions. For Pigeon 553, response rates were decreased during the VT 30-s test condition, but no systematic differences between components were observed. During the VT 15-s test condition, response rate decreases were only slightly more pronounced during the 1-s food component. Finally, during the VT 5-s test condition, response rates decreased across test sessions and the decreases were larger during the 1-s food component.

Figure 14 shows the proportion of baseline ET50 during the 1-s food components (open triangles) and 6.5-s food components (filled diamonds) during each VT 30-, 15-, and 5-s sessions for each pigeon. For Pigeon 858, during the VT 30-s test condition, the ET50 increased and then decreased below baseline levels during the 1-s food component. The ET50 decreased across test sessions during the 6.5-s food component. During the VT 15- and 5-s test conditions, the ET50 decreased and the decreases were more marked during the 1-s component than during the 6.5-s food component. For Pigeon 738, during the VT 30-s test condition, the ET50 approximated baseline levels or decreased during the 1-s food component, while it increased above baseline during the 6.5-s food component. During the VT 15-and 5-s test conditions, the ET50 was decreased but only slightly lower during the 1-s food component than during the 6.5-s food component. For Pigeon 562, the ET50 during the 1-s food component was decreased while increased during the 6.5-s food component during the VT 30-s test condition. During the VT 

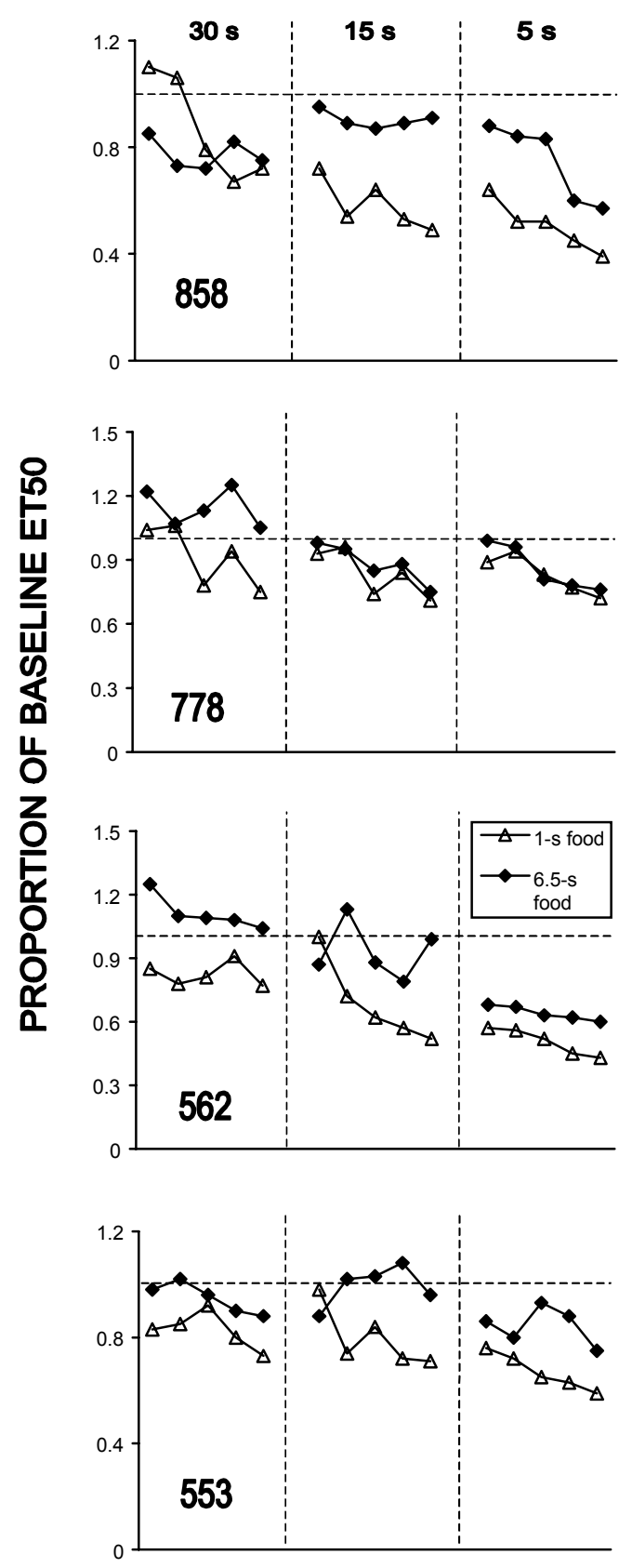

\section{VT SESSIONS}

Figure 14. Proportion of baseline ET50 during 1-s food components (open triangles) and 6.5-s food components (filled diamonds) during each VT 30-, 15-, and 5-s session for each pigeon. The horizontal line indicates a proportion of 1.0 or no change from baseline. Note: the y-axes are scaled differently for each pigeon. 
15-s test condition, the ET50 was decreased during the 1-s food component. During the 6.5-s food component, the ET50 was below baseline levels on 3 out of 5 sessions, and at or slightly above baseline levels for the remaining two sessions. Decreases in the ET50 were more pronounced during the 1-s food component. During the VT 5-s test condition, the ET50 was decreased even further and the decreases were larger during the 1-s food component than during the 6.5-s food component. For Pigeon 553, the ET50 was decreased and, with the exception of the first session of the VT 15-s test condition, the decreases were more marked during the 1-s food component than during the 6.5-s food component. In summary, when the ET50 was disrupted, on most occasions it was more disrupted during the 1-s food component than during the 6.5-s food component. In addition, the ET50 was decreased, rather than increased. When the ET50 increased, it occurred most often during the 6.5-s food component.

Figure 15 shows the proportion of baseline response rates during 1-s food components (open triangles) and 6.5-s food components (filled diamonds) during each prefeeding session for each pigeon. The horizontal line indicates a proportion of 1.0 or no change from baseline. In general, response rates were not systematically increased or decreased across sessions until responding was eliminated during the final prefeeding session (see Table 2 for the largest amount of food given and consumed during prefeeding test conditions). For Pigeon 858, response rates were slightly increased during the first eight sessions of prefeeding during 1-s food component, and slightly increased or decreased during the 6.5-s food component. During most sessions, response rates were slightly more disrupted during the 6.5-s food component, with the exception of the session preceding response elimination. For Pigeon 778, during the first six sessions, response rates were either the same as or increased above baseline during the 1-s food component and were either the same as or slightly decreased below baseline during the 6.5-s 

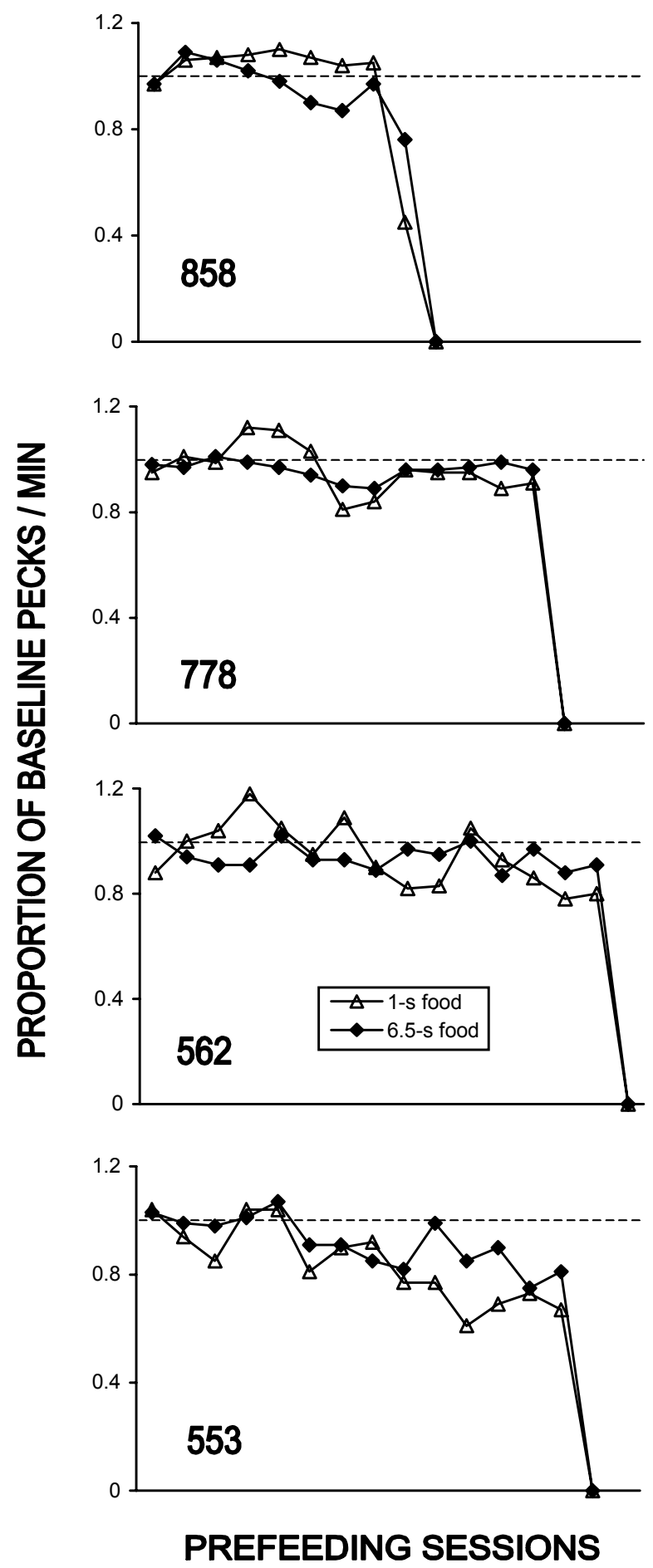

Figure 15. Proportion of baseline response rates (pecks/min) during 1-s food components (open triangles) and 6.5-s food components (filled diamonds) during each prefeeding session for each pigeon. The horizontal line indicates a proportion of 1.0 or no change from baseline. 
food component. During the last seven sessions in which responding occurred, response rates were decreased below baseline and decreases were either the same in both components or slightly more pronounced during the 1-s food component. For Pigeon 562, during the first session, response rates were slightly increased above baseline during the 6.5 -s food component and decreased below baseline during the 1-s food component. During the second through the seventh test sessions, response rates increased above baseline during the 1-s food component and decreased below baseline during the 6.5-s food. During the remainder of the sessions, response rates were generally lower than during baseline, and the decreases were larger during the 1-s food component, with the exceptions of sessions 11 and 12. For Pigeon 553, response rates tended to decrease as a function of test session, and decreases were greater during the 1-s food component.

Figure 16 shows the proportion of baseline ET50 during 1-s food components (open triangles) and 6.5-s food components (filled diamonds) during each prefeeding session for each pigeon. The horizontal line indicates a proportion of 1.0 or no change from baseline. In general, the ET50 during the 6.5-s food component was increased above or remained the same as baseline. The ET50 during the 1-s food component was decreased below or remained the same as baseline. With the exception of several sessions for Pigeons 562 and 553, the changes in ET50 were more pronounced during the 1-s food component. Thus, on most sessions, prefeeding produced underestimations of time during the 6.5-s food component and overestimations of time during the 1-s food component.

\section{Discussion}

The results of Experiment 2 are also consistent with research using the FOPP: response rates on the left key were high during the early part of the intervals and then decreased to low or 


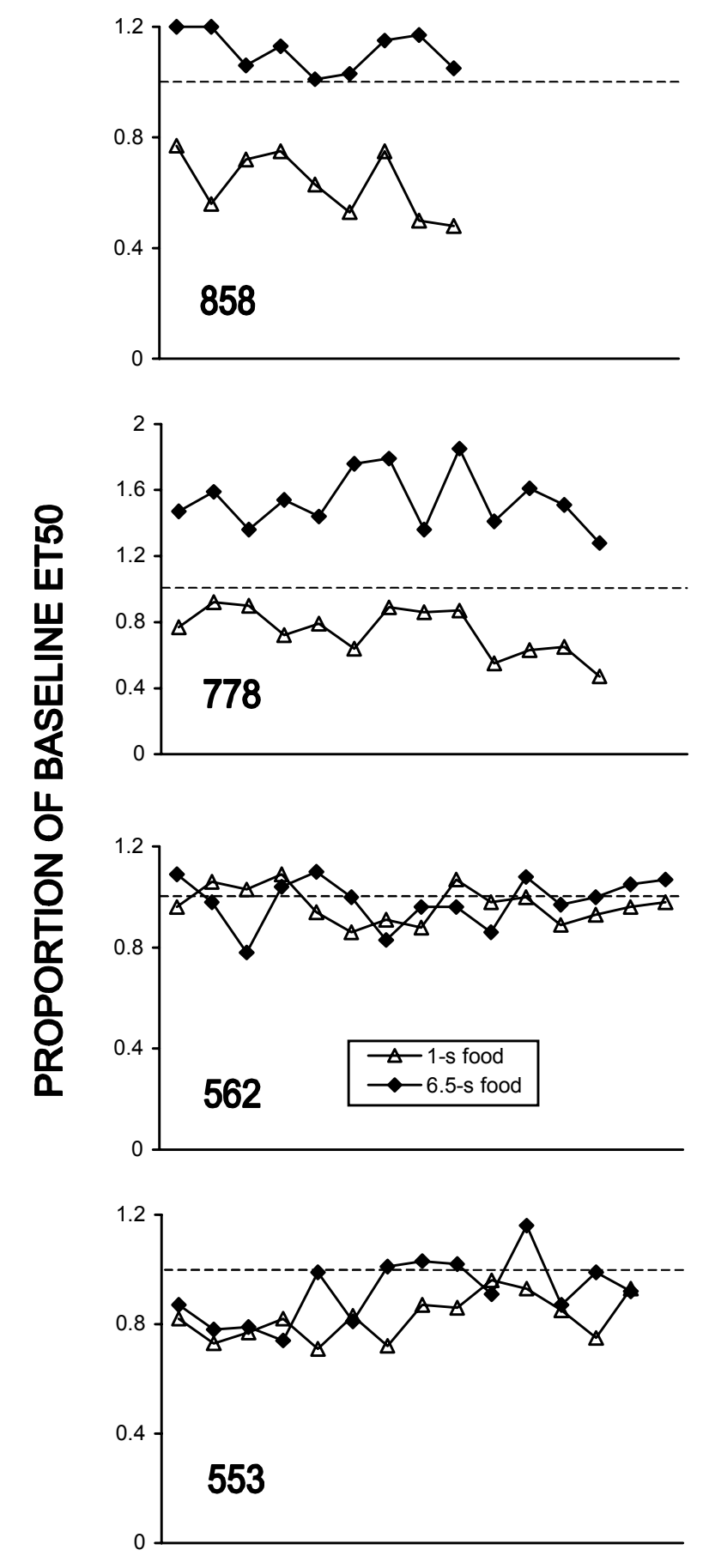

PREFEEDING SESSIONS

Figure 16. Proportion of baseline ET50 during 1-s food components (open triangles) and 6.5-s food components (filled diamonds) during each prefeeding session for each pigeon. The horizontal line indicates a proportion of 1.0 or no change from baseline. Note: the y-axis is scaled differently for Pigeon 778. 
zero rates, while response rates on the right key were low during the early portions of the intervals and then increased to high rates for the remainder of the intervals. In addition, the proportion of right key pecks were low during the early portions of the intervals and then increased to asymptotic levels during the second portion of the intervals (Bizo \& White, 1994a, 1994b; Stubbs, 1968, 1979, 1980). There also was a difference in baseline performance in ET50 between the lean and rich components of the multiple schedule that was consistent with the BeT: when responding was maintained by a longer reinforcer duration, the ET50 was usually lower than during the component with a shorter reinforcer duration, consistent with an overestimation of time, which replicates the findings of Grace and Nevin (2000).

Similar to Experiment 1, there may be a few occasions where order effects occurred. For example, for Pigeon 778, the ET50 data seem to track the experimental conditions. For this pigeon, the VT test conditions were conducted first and were conducted in descending order (beginning with the VT 5-s test condition). Examination of Figure 14 shows that during the VT 5-s test condition, the ET50 was not largely differentially disrupted in either component. A comparable effect was obtained during the VT 15-s test condition, in which the ET50 for 1-s food component was only slightly more disrupted than during the 6.5 -s food component. Finally, during the VT 30-s component, the ET50 was increased above baseline during the 6.5-s food component and decreased below baseline during the 1-s food component. Repeated exposure to the testing conditions may have produced a recalibration of timing.

There were also differences across baseline ET50s for Pigeon 562 (see Figure 12). These differences, however, do not seem to be the product of order effects. For this pigeon, prefeeding was the first test condition and was then followed by the VT test conditions presented in ascending order (beginning with the VT 30-s test condition). Upon returning to baseline after the 
prefeeding test condition, the ET50 during the 6.5-s food component was higher than sessions preceding prefeeding. Additional sessions were conducted to ascertain whether the ET50 would return to previously obtained levels, but without success. After the VT 30-s test condition, however, the ET50 returned to levels approximating the first baseline condition. The results of prefeeding and the VT test conditions do not seem to differ from the performance of pigeons in which performance was stable across the different baseline conditions (see Figures 14 and 16). In this case, an increased difference between baseline ET50s during the two components do not seem to be predictive of large or small increases in the ET50 during the 6.5-s food component, as discussed in Experiment 1.

Thus, as shown in Experiment 1, the results from the VT test conditions of the present experiment seem to replicate and extend the findings of Grace and Nevin (2000) when using the peck procedure to assess differences in timing and response strength with different reinforcer durations. Similarly, the present experiment extends the findings of Grace and Nevin (2000) by testing a range of VT values and finding that, in most cases, the level of disruption was a function of the value of the VT. Grace and Nevin (2000) also found slight increases in the peak time during the component with longer reinforcer durations.

Finally, any interpretation of the prefeeding data should be tentative in that no large systematic differences were observed between response rates during the 6.5-s and 1-s food components. The ET50 during the 6.5-s food component, however, was often more resistant to the disruptive effects of prefeeding than during the 1-s food component. On most occasions, the ET50 during the 1-s food component was reduced below baseline, while the ET50 during the 6.5-s food component was increased above baseline. Therefore, although the data from the VT test conditions seem to replicate those found by Grace and Nevin (2000), most of the prefeeding 
data do not. Grace and Nevin (2000), however, only tested prefeeding amounts of 20, 40, and 60 g. If the functions in the present experiment are truncated to only include the largest amounts of prefeeding (i.e., $22.5 \mathrm{~g}$ and above), the results are a little bit more promising. In three out of four pigeons $(778,562$, and 553, see Figure 15), response rates are more disrupted during the 1-s food component than during the 6.5-s food component. For Pigeon 858, the first test session using $22.5 \mathrm{~g}$ of prefeeding food eliminated responding. If the session prior to this is examined, the results are consistent with Grace and Nevin (2000). This effect will be discussed in more detail in the General Discussion.

\section{General Discussion}

In Experiment 1, in which the effects of different reinforcement rates on timing and response strength were tested using a multiple schedule comprised of FOPP trials, responding was typical of FOPP performance: left-key response rates were high during the early portions of the interval and decreased to near-zero or zero levels later in the interval while right-key response rates were low during the early portions of the interval and increased to asymptotic levels during the later parts of the interval. These results also were reflected in the proportion of right key peck data. Both response rates and ET50 were different between rich and lean components during baseline conditions: response rates tended to be higher and ET50s were lower during the VI 30-s component than during the VI 120-s component. During VT test conditions, on most occasions, response rates and ET50s were more resistant to change during the VI 30-s component than during the VI 120-s component. The level of disruption tended to be dependent upon the value of the VT schedule (i.e., behavior was disrupted more the higher the rate of response-independent food delivery). During the prefeeding test condition, the data are not quite as clear. For two pigeons (545 and 510), response rates during the VI 30-s component 
were more resistant to change than during the VI 120-s component, while the opposite is true for the remaining two pigeons (738 and 573). The ET50 was often increased above baseline during the VI 30-s component and decreased below or remained the same as baseline during the VI 120s component.

Comparable effects were found in Experiment 2, in which the effects of different reinforcer durations on timing and response strength were tested in a multiple schedule comprised of FOPP trials. Left-key response rates decreased as a function of time in the interval while right-key response rates increased as a function of time in the interval. Both response rates and ET50s were different during baseline conditions between components with long and short reinforcer durations: response rates were higher and the ET50s were lower during the 6.5-s food component than during the 1-s food component. During the VT test conditions, response rates and ET50s tended to be more resistance to change during the 6.5-s food component than during the 1-s food component. Similar to Experiment 1, the level of disruption tended to be dependent upon the value of the VT schedule. During the prefeeding test condition, the data are a little more consistent with those from the VT test conditions, relative to Experiment 1, particularly if the functions are truncated to include only the largest amount of prefeeding, like those used in Grace and Nevin (2000). In most cases, response rates and the ET50s were more resistant to change during the 6.5-s food component than during the 1-s food component.

The results of the present experiment, in general, replicate and extend those of Grace and Nevin (2000) in which a multiple schedule comprised of FI and peak trials was used to assess the effects on reinforcement rates and reinforcer durations on temporal control and response strength. During VT test conditions, Grace and Nevin (2000) tested only one VT value, while the present experiment tested three different values. There also were differences in the prefeeding 
amounts tested in Grace and Nevin (2000) and the present experiment: Grace and Nevin (2000) tested 20 and $40 \mathrm{~g}$ for one session each, and then $60 \mathrm{~g}$ until responding was eliminated. Examining only the data from sessions using larger amounts of prefeeding during Experiment 1 did not yield results consistent with Grace and Nevin (2000). For two of the pigeons (738 and 573), response rates were more resistant during the VI 120-s component than during the VI 30-s component. Truncating the functions for Experiment 2, on the other hand, does yield results consistent with Grace and Nevin (2000).

The data from the prefeeding test condition, particularly those from Experiment 1, are somewhat more difficult to interpret. On many occasions, response rates and ET50s were disrupted during the first session of prefeeding and either did not change greatly or varied unsystematically during the remainder of the test sessions until responding was eliminated. Given that these results were obtained in most of pigeons from both Experiments 1 and 2, it suggests that perhaps there was either a problem with this particular procedure or with the manner in which the prefeeding test was conducted. With respect to using the FOPP to assess the effects of different reinforcement rates and reinforcer durations on temporal control and response strength, the predicted effects were obtained when responding was disrupted using responseindependent food delivery during the ITI. This suggests that the present procedure is sufficiently sensitive to detect consistent differences in temporal control and response strength.

Thus, it may be the case that there was a problem with the prefeeding procedure itself. The effects of response-independent food delivery and prefeeding are often considered comparable disruptors relative to, for example, extinction (Bell, 1999; Nevin, 1992; Nevin, Mandell, \& Atak, 1983). Response-independent food delivery and prefeeding are considered "off-baseline" because tests can be conducted without altering the contingencies in effect during 
the component in which responding occurs, unlike extinction, when reinforcement is eliminated (Grace \& Nevin, 2000; Morgan, Killeen, and Fetterman, 1993). Thus, even though responseindependent food delivery is conducted during experimental sessions and prefeeding is conducted prior to experimental sessions, it is often the case that both disruptors have similar effects on behavior.

Research on timing has also shown that there are few differences in the effects of manipulating reinforcement rate prior to or during an experimental session. For example, Morgan, Killeen, and Fetterman (1993) examined the effects of changing the reinforcement rates correlated with a temporal stimulus both before and during the experimental sessions, but the effects of changing reinforcement rates were the same, regardless of when the manipulation occurred. In fact, it is rather difficult, if not impossible, to find an example in the literature in which response-independent food delivery during the ITI and prefeeding produce inconsistent results, although there are several experiments that test only response-independent food delivery and extinction (e.g., Nevin, 1974; Nevin, Mandell, \& Atak, 1983). Perhaps there are occasions in which prefeeding produces inconsistent results, but those data are not included in publications (or perhaps that is just wishful thinking on the part of the author).

There was one published study examining the effects of prefeeding on temporal discrimination in which prefeeding had no clear effect. Ferguson and Paule (1995) trained rats to hold a lever in the depressed position for a minimum of $10 \mathrm{~s}$ but not longer than $14 \mathrm{~s}$. A lever release within the 4-s window produced reinforcement. In this procedure, therefore, the dependent measure of accuracy (the total number of correct lever holds divided by the total number of lever holds multiplied by 100) was the index of temporal discrimination. During baseline sessions, rats received their entire daily allotment of food immediately after each session 
(23 $\mathrm{h}$ prior to the next session). During test sessions, the daily allotment of food was given between $15 \mathrm{~min}$ and $6 \mathrm{~h}$ prior to the experimental session. Prefeeding did not consistently affect accuracy on the temporal discrimination procedure. It is worth noting, therefore, that the present experiment is not the only one to produce results that are inconsistent with the response strength literature despite the procedural differences in the present experiment and the experiment conducted by Ferguson and Paule (1995). It suggests that this particular problem is worth investigating further empirically. Unfortunately, the reasons for the effects of prefeeding in the present set of experiments remain unclear.

One potential problem with the prefeeding data from the present set of experiments may be the manner in which the data were interpreted. Examining response strength typically involves applying some disruptive force that tends to decrease response rates. Thus, "disruption" normally is defined in terms of the extent to which responding is decreased or eliminated. The present set of experiments, in addition to Grace and Nevin (2000), also examined the effects of disruptive forces on the non-traditional measure of timing. In the present experiment and Grace and Nevin (2000), those data were interpreted in a manner consistent with the way in which response rate data are analyzed: disruption is defined in terms of the extent to which the timing index was decreased. Interpreting the data somewhat differently, however, suggests that timing was disrupted in an interesting way by prefeeding. In Figures 8 and 16, there are many occasions in which the ET50s during the lean components were not substantially reduced or even changed from baseline levels. The ET50s during the rich components, however, were often increased above baseline levels, and on some occasions, considerably so. Thus, if the absolute change from baseline is examined, disregarding the direction in which those changes occurred, timing was more disrupted during the rich components than during the lean components. In addition, those 
changes occurred in the opposite direction that was predicted by the BeT (i.e., addition of food during prefeeding should have decreased the ET50). Grace \& Nevin (2000) also found that in some cases the peak time was increased with the addition of response-independent food delivery during the ITI and prefeeding. Therefore, the data from the present experiment and Grace and Nevin (2000) might provide an interesting challenge to the predictions of the BeT and suggest that additional experiments should be conducted to clarify the discrepancy in the data.

An additional area in which further empirical investigation may be needed is in behavioral pharmacology. The effects of drugs from several pharmacological classes on timing have been well characterized (e.g., Knealing \& Schaal, 2002; Kraemer, Randall, Dose, \& Brown, 1997; Maricq, Roberts, \& Church, 1981), in that drugs tend to produce an overestimation of time similar to those produced by improving reinforcement conditions. Given the consistency of these effects, it may be worth exploring the effects of drugs as disruptors using the baseline procedure used in the present set of experiments. Although drugs are not traditionally considered disruptors in the response strength literature, there is a growing body of literature suggesting that drugs often have comparable effects on behavior to those produced by more traditional disruptors (e.g., Egli, Schaal, Thompson, \& Cleary, 1992; Hoffman, Branch, \& Sizemore, 1987; Jensen \& Thompson, 1982; Odum, Haworth, \& Schaal, 1998; Ross \& Schaal, 2002; Schaal, Miller, \& Odum, 1995). For example, Egli, Schaal, Thompson and Cleary (1992) examined the effects of two opioids, buprenorphine and methadone, on responding maintained by a five-ply multiple schedule, which arranged five different reinforcement schedules (VI 5, 10, 30, 75, and $150 \mathrm{~s}$ ). As the mean reinforcer interval increased, response rates decreased. Methadone and buprenorphine decreased response rates dose dependently and response rates maintained by the lower reinforcement rates (VI 75 and $150 \mathrm{~s}$ ) were generally more disrupted than responding maintained 
by higher response rates. The advantage to examining the effects of drugs on temporal control and response strength is that the effects of drugs on timing are well documented, whereas the effects of prefeeding and response-independent food delivery are not.

\section{Conclusions}

The present set of experiments had several goals, the first of which was to determine whether disruption would produce systematic differences in both temporal control and response strength. The second goal was to determine whether the disruptive effects of responseindependent food delivery and prefeeding would be consistent with current timing theories. The final goal was to determine whether the baseline differences in performance between rich and lean components would be similar to those obtained by Grace and Nevin (2000).

\section{Effects of the disruptors.}

Because the $\mathrm{BeT}$ is based on the assumption that reinforcement variables determine the discrimination of a temporal stimulus, it makes predictions about the effects of adding responseindependent food delivery and prefeeding. Specifically, because both disruptors increase the overall access to food for the pigeons, it was expected that both would have comparable effects to those of increasing the rate of reinforcement, for example. That is, adding responseindependent food delivery or prefeeding should decrease the ET50, or produce an overestimation of time. The effects of disruptors on FOPP performance provided partial support for the predictions of the BeT. During the VT test conditions, the ET50 was either decreased or was not systematically changed during the lean components (i.e., VI 120-s and 6.5-s food components). During, the rich components, the ET50 was most often decreased below baseline levels, but on occasion, increased above baseline. As noted previously some of these increases may be due to floor effects because the baseline ET50 was relatively low for some pigeons prior to testing. 
The data from prefeeding test sessions also provide partial support for the predictions of BeT. For most of the pigeons, the ET50 was decreased below baseline during the lean components (VI 120-s and 1-s food components). During the rich components, on most sessions and for most of the pigeons, the ET50 tended to increase above baseline levels. Thus, most of the data during the lean components are consistent with the predictions made by the BeT, while the data from the rich components often tend to be the opposite of what BeT predicts. The data on which these statements are based are not entirely consistent, therefore these conclusions are tentative at best. When viewed together with the results of Grace and Nevin (2000), however, a stronger point can be made that the predictions of $\mathrm{BeT}$ are often correct in terms of the effects of these disruptors on temporal control. It may be of interest to examine disruptors about which the $\mathrm{BeT}$ does not make specific predictions, such as distracting stimuli. It may be the case that the effects of disruption on temporal control may only occur when the disruptors alter the overall rate of reinforcement (or total amount of food consumed).

\section{Baseline differences in performance.}

As discussed above, in both Experiments 1 and 2, differences in baseline ET50s were observed: ET50s tended to be higher during the lean components (VI 120-s and 1-s food components) than during the rich components (VI 30-s and 6.5s- food components). These results are consistent with those of Grace and Nevin (2000), but inconsistent with the results of other experiments (Bizo \& White, 1994a; Haight \& Killeen, 1991; Killeen \& Fetterman, 1988; Morgan, Killeen, \& Fetterman, 1993). The BeT assumes that when changes in reinforcement parameters produce changes in the pacemaker rate (reflected in changes of the ET50), a corresponding change will occur in the behavioral states associated with timing. In order to maintain accurate performance, new behaviors will become correlated with the later states and 
then serve as cues for timing. One obvious difference between the present experiments and Grace and Nevin (2000), which found differences in the baseline ET50s depending upon the reinforcement variables, and those that report no difference between baseline ET50s (Bizo \& White, 1994a; Haight \& Killeen, 1991; Killeen \& Fetterman, 1988; Morgan, Killeen, \& Fetterman, 1993) is that the experiments producing differences in baseline performance were conducted using multiple schedules. In the present experiments and Grace and Nevin (2000), trial durations ranged from $30 \mathrm{~s}$ up to $90 \mathrm{~s}$ and ITI's were either 15 or $20 \mathrm{~s}$. It may be the case the in order for recalibration to occur, a sufficient amount of exposure to novel contingencies must occur. For example, when reinforcement manipulations are conducted across sessions, it often takes several sessions before responding recalibrates and adjusts to the new reinforcement contingencies (Bizo \& White, 1994a; Haight \& Killeen, 1991; Killeen \& Fetterman, 1988; Morgan, Killeen, \& Fetterman, 1993). Changing the contingencies every one to two minutes may not provide sufficient exposure to the new contingencies for recalibration to occur. The present set of experiments was not designed to test this idea, but an experiment could easily be conducted that directly compares the effects of altering reinforcement conditions on temporal control either across or within sessions, or by extending the component durations in which the different contingencies are in effect. The results of experiments like this would not only shed light on some of the inconsistencies in the timing literature, but it may also have implications for examining the effects of disruptors on temporal control and response strength. In both the present experiments and the experiments of Grace and Nevin (2000), baseline differences in ET50s were present. Perhaps differences in the resistance to disruption of the ET50 (or any timing index) based on different reinforcement parameters will only occur when baseline differences are present. 


\section{Temporal Control and Response Strength.}

The main question of interest in the present set of experiments was to determine if temporal control and response strength would systematically differ when responding was disrupted. In general, this seems to be the case. The results of the present experiments replicate those found by Grace and Nevin (2000) in that response-independent food delivery and prefeeding tended to disrupt both response rates and ET50s less during the VI 30-s and 6.5-s food components than during the VI 120-s and 1-s food components. There are, however, exceptions to this statement. There are occasions in both experiments in which the opposite was true, particularly the troublesome prefeeding data. In addition, there are instances where the two dependent measures vary independently from another, providing support for the notion that the index of timing and response rates are orthogonal. For example, in Experiment 1, for Pigeon 545, there are no large consistent differences between response rates in the two components during VT 30- and 15-s test conditions, while there are relatively large differences in the ET50 (see Figures 5 and 6). In this case, resistance to disruption of response rates is not predictive of resistance to disruption of the ET50 because proportion of baseline response rates were either the same, higher or lower during the VI 30-s component relative to the VI 120-s component. Proportion of baseline ET50s, on the other hand, were higher during the VI 120-s component on VT 30-s test sessions and lower on VT 5-s test sessions than the VI 30-s component. Similarly, for Pigeon 738, systematic differences were not observed between ET50s in either component during the VT 15- and 5-s test conditions, whereas consistent differences were seen in the proportion of baseline response rates for the same sessions (see Figures 5 and 6).

Similar inconsistencies are present in the data from Experiment 2. For example, for Pigeon 778, relatively large differences are seen in the proportion of baseline response rates 
during the VT 15- and VT 5-s test conditions, while very little differences are seen in the proportion of baseline ET50s for the same sessions (see Figures 13 and 14). Likewise, for Pigeon 553, differences in proportion of baseline response rates are not observed until the VT 5-s test condition, while differences in proportion of baseline ET50s occur in all of the VT test conditions. Therefore, across both experiments, there are instances where both response rates and ET50s vary in a consistent manner, where response rates are disrupted but ET50s do not change, and where ET50s change and response rates remain the same, suggesting that the two measures are mutually independent. Of course, many of these exceptions are from pigeons that showed order effects, so conclusions drawn from these data are not definitive. Thus, on the whole, the data from the present experiment are consistent with those of Grace and Nevin (2000) in that response strength and temporal control are determined by reinforcement variables and are disrupted in a way consistent with research on response strength. Comparisons between the present experiments and those of Grace and Nevin (2000) are somewhat difficult due to the fact that only data averaged across all the subjects are presented, although the variability across subjects and sessions seems to be minimal. The data from the present experiments, taken into account with the data from Grace and Nevin (2000) suggest that assessing the effects of disruption on temporal control and response strength is worth pursuing by conducting further empirical investigations, perhaps using different disruptors (e.g., drugs, distracting stimuli) or manipulating different reinforcement parameters (e.g., reinforcement probability or immediacy).

\section{Summary}

The results of the present experiments are mostly consistent with other research examining the effects of disruption on temporal control and response strength when different reinforcement rates or reinforcer durations maintain behavior. In general, the findings of the 
present experiment generally replicate those of Grace and Nevin (2000) in three ways. First, proportion of baseline response rates and ET50s tended to vary in a manner consistent with predictions made from the response strength literature: response rates and ET50s were more resistant to disruption when behavior was maintained by high rates of reinforcement and long reinforcer durations than when behavior was maintained by low rates of reinforcement and short reinforcer durations. Second, the effects of response-independent food delivery and prefeeding provided partial support for the predictions of the BeT, particularly when behavior was maintained by low rates of reinforcement and short reinforcer durations. Finally, using a multiple schedule to assess the effects of different rates of reinforcement and reinforcer durations produced differences in the baseline temporal estimations: improved reinforcement conditions tended to decrease the ET50 relative to poor reinforcement conditions. There are exceptions, however, to all of these statements in both the present experiments and the experiments of Grace Nevin (2000). Further research is needed to examine the relation between temporal control and response strength, perhaps by using non-traditional disruptors (e.g., drugs, distracting stimuli) and other reinforcement parameters (e.g., reinforcement probability and immediacy), which are studied when examining response strength, but not temporal control. 


\section{References}

Bell, M. C. (1999). Pavlovian contingencies and resistance to change in a multiple schedule. Journal of the Experimental Analysis of Behavior, 72, 81 - 96.

Bizo, L. A., \& White, K. G. (1994a). The behavioral theory of timing: Reinforcer rate determines pacemaker rate. Journal of the Experimental Analysis of Behavior, 61, 19 - 33 .

Bizo, L. A., \& White, K. G. (1994b). Pacemaker rate in the behavioral theory of timing. Journal of Experimental Psychology: Animal Behavior Processes, 20, 308 - 321.

Catania, A. C. (1970). Reinforcement schedules and psychophysical judgements: A study of some temporal properties of behavior. In W. N. Schoenfeld (Ed.), The Theory of Reinforcement Schedules. New York: Appleton-Century-Crofts.

Chiang, T. -J., Al-Ruwaitea, A. S. A., Ho, M. -Y., Bradshaw, C. M., \& Szabadi, E. (1999). Effect of central 5-hydroxytryptamine depletion on performance on the free-operant psychophysical procedure: Facilitation of switching, but no effect on temporal differentiation of responding. Psychopharmacology, 143, $166-173$.

Church, R. M., \& Deluty, M. (1977). Bisection of temporal intervals. Journal of Experimental Psychology: Animal Behavior Processes, 3, 216 - 228.

Egli, M., Schaal, D. W., Thompson, T., \& Cleary, J. (1992). Opioid-induced responserate decrements in pigeons responding under variable-interval schedules: Reinforcement mechanisms. Behavioural Pharmacology, 3, $581-591$.

Ferguson, S. A., \& Paule, M. G. (1995). Lack of effect of prefeeding on food-reinforced temporal response differentiation and progressive ratio responding. Behavioural Processes, 34, $153-160$. 
Fetterman, J. G., \& Killeen, P. R. (1991). Adjusting the pacemaker. Learning and Motivation, 22, $226-252$.

Fleshler, M., \& Hoffman, H. S. (1962). A progression for generating variable-interval schedules. Journal of the Experimental Analysis of Behavior, 5, 529 - 530.

Gibbon, J. (1977). Scalar expectancy theory and Weber's law in animal timing. Psychological Review, 84, 279 - 325.

Gibbon, J., \& Church, R. M. (1981). Time left: Linear versus logarithmic subjective time. Journal of Experimental Psychology: Animal Behavior Processes, 7, 87 - 108.

Gibbon, J., Church, R. M., \& Meck, W. H. (1984). Scalar timing in memory. In J. Gibbon \& L. Allan (Eds.), Annals of the New York Academy of Sciences, Vol. 423. Timing and time perception, (pp. $52-77)$.

Grace, R. C., \& Nevin, J. A. (2000). Response strength and temporal control in fixed interval schedules. Animal Learning and Behavior, 28, 313 - 331.

Grace, R. C., Schwendiman, J. W., \& Nevin, J. A. (1998). Effects of unsignaled delay of reinforcement on preference and resistance to change. Journal of the Experimental Analysis of Behavior, 69, $247-261$.

Haight, P. A., \& Killeen, P. R. (1991). Adjunctive behavior in multiple schedules of reinforcement. Animal Learning \& Behavior, 19, 257 - 263..

Harper, D. N. (1996). Response-independent food delivery and behavioral resistance to change. Journal of the Experimental Analysis of Behavior, 65, 549 - 560.

Hoffman, S. H., Branch, M. N., \& Sizemore, G. M. (1987). Cocaine tolerance: Acute versus chronic effects as dependent upon fixed-ratio size. Journal of the Experimental Analysis of Behavior, 47, 363-376. 
Jensen, M. A., \& Thompson, T. I. (1982). Interaction of methadone and pentobarbital on chained fixed-interval performance in pigeons. Pharmacology, Biochemistry \& Behavior, 16, $271-278$.

Killeen, P. R. (1991). Behavior's time. In G. Bower (Ed.), The Psychology of Learning and Motivation, Vol. 27 (pp. 294 - 334). New York: Academic Press.

Killeen, P. R., \& Fetterman, J. G. (1988). A behavioral theory of timing. Psychological Review, 95, $274-295$.

Killeen, P. R. \& Fetterman, J. G. (1993). The behavior theory of timing: Transition analyses. Journal of the Experimental Analysis of Behavior, 59, 411 - 422.

Knealing, T. W., \& Schaal, D. W. (2002). Disruption of temporal organized behavior by morphine. Journal of the Experimental Analysis of Behavior, 77, 157 - 169.

Kraemer, P. J., Randall, C. K., Dose, J. M., \& Brown, R. W. (1997). Impact of $d$ amphetamine on temporal estimation in pigeons tested with a production procedure. Pharmacology, Biochemistry, and Behavior, 58, 323 - 327.

Laties, V. G., Weiss, B., Clark, R. L., \& Reynolds, M. D. (1965). Overt "mediating" behavior during temporally spaced responding. Journal of the Experimental Analysis of Behavior, 8, $107-116$.

Laties, V. G., Weiss, B., \& Weiss, A. B. (1969). Further observations on overt "mediating" behavior and the discrimination of time. Journal of the Experimental Analysis of Behavior, 12, $43-57$.

MacEwen, D., \& Killeen, P. R. (1991). The effects of rate and amount of reinforcement on the speed of the pacemaker in pigeons' timing behavior. Animal Learning and Behavior, 19, $164-170$ 
Maricq, A. W., Roberts, S., \& Church, R. M. (1981). Methamphetamine and time estimation. Journal of Experimental Psychology: Animal Behavior Processes, 7, 18 - 30.

Morgan, L., Killeen, P. R., \& Fetterman, J. G. (1993). Changing rates of reinforcement perturbs the flow of time. Behavioural Processes, 30, $259-272$.

Morrisey, G., Ho, M. -Y., Wogar, M.A., Bradshaw, C. M., \& Szabadi, E. (1994). Effects of lesions of the ascending 5-hydroxytryptaminergic pathways on timing behaviour investigated with fixed-interval peak procedure. Psychopharmacology, 114, $463-468$.

Morrisey, G., Wogar, M.A., Bradshaw, C. M., \& Szabadi, E. (1993). Effects of lesions of the ascending 5-hydroxytryptaminergic pathways on timing behaviour investigated with an interval bisection task. Psychopharmacology, 112, $80-85$.

Nevin, J. A. (1974). Response strength in multiple schedules. Journal of the Experimental Analysis of Behavior, 21, 389-408.

Nevin, J. A. (1984). Pavlovian determiners of behavioral momentum. Animal Learning and Behavior, 12, $363-370$.

Nevin, J. A. (1992). An integrative model for the study of behavioral momentum. Journal of the Experimental Analysis of Behavior, 57, $301-316$.

Nevin, J. A., Mandell, C., \& Atak, J. R. (1983). The analysis of behavioral momentum. Journal of the Experimental Analysis of Behavior, 39, 49 - 59.

Odum, A. L., Haworth, S. C., \& Schaal, D. W. (1998). Food-deprivation level alters the effects of morphine on pigeons' key pecking. Journal of the Experimental Analysis of Behavior, $69,295-310$.

Rau, J. C., Pickering, L. D., McLean, A. P. (1996). Resistance to change as a function of concurrent reinforcer magnitude. Behavioural Processes, 38, 253 - 264. 
Roberts, S. (1981). Isolation of an internal clock. Journal of Experimental Psychology: Animal Behavior Processes, 7, 242 - 268.

Ross, L., \& Schaal, D. W. (2002). Time of supplemental feeding alters the effects of cocaine on lever pressing of rats. Journal of the Experimental Analysis of Behavior, 77, 199-208.

Schaal, D. W., Miller, M. A., \& Odum, A. L. (1995). Cocaine's effects on foodreinforced pecking in pigeons depend on food-deprivation level. Journal of the Experimental Analysis of Behavior, 64, 61-73.

Skinner, B. F. (1938). The Behavior of Organisms. Acton, MA: Copley Publishing Group.

Stubbs, D. A. (1968). The discrimination of stimulus duration by pigeons. Journal of the Experimental Analysis of Behavior, 11, 223 - 238.

Stubbs, D. A. (1979). Temporal discrimination and psychophysics. In M. D. Zeiler \& P. Harzem (Eds.), Advances in the Analysis of Behavior: Vol. 1. Reinforcement and the Organization of Behavior (pp. 341 - 369). Chichester, England: Wiley.

Stubbs, D. A. (1980). Temporal discrimination and a free-operant procedure. Journal of the Experimental Analysis of Behavior, 33, 167 - 185. 